Research Article

\title{
Optimizing the Compaction Characteristics and Strength Properties of Gravelly Soils in terms of Fine Contents
}

\author{
Mingzhi Zhao $\left.\mathbb{D}^{1}\right)^{1,2}$ Gang Liu $\mathbb{D}^{1,2}$ Longxiang Deng $\mathbb{D}^{1,2}$ and Yangang Li $\mathbb{D}^{1,2}$ \\ ${ }^{1}$ School of Civil Engineering,Architecture and Environment, Xihua University, Chengdu 610039, Sichuan, China \\ ${ }^{2}$ Institute of Geotechnical Engineering, Xihua University, Chengdu 610039, Sichuan, China \\ Correspondence should be addressed to Gang Liu; liugang_leo@126.com
}

Received 12 November 2020; Revised 14 December 2020; Accepted 4 January 2021; Published 21 January 2021

Academic Editor: Georgios I. Giannopoulos

Copyright (C) 2021 Mingzhi Zhao et al. This is an open access article distributed under the Creative Commons Attribution License, which permits unrestricted use, distribution, and reproduction in any medium, provided the original work is properly cited.

Gravelly soils are widely adopted as civil construction materials in engineering practice. Although the influence mechanism of fine contents (FCs) on the mechanical behavior of gravelly soils has been emphasized in the previous studies, few discuss the compaction and strength properties concurrently. Besides, FCs of gravelly soils were discussed separately in many cases regardless of the variation in water content. In this study, modified Proctor compaction test and medium-sized triaxial test were performed to investigate the mechanical properties of gravelly soils containing different magnitudes of fine contents. It is shown that an optimum FC exists for gravelly soils although the value of the optimum FC varies with grading curves of the coarse-grained portion. By adjusting FC in the gravelly soils, not only could the maximum dry density $\rho_{d \max }$ be improved but also the optimum saturation degree $S_{r o p t}$ rises significantly, and synchronously, the minimum air void ratio $v_{a \text { min }}$ decreases notably. Besides, fine particles are just right to fill with the voids formed by the coarse-grained skeleton for the optimum FC sample. The soil structure corresponding to the optimum FC status can be termed as a densely filled skeleton structure, which is the densest and most stable. As fine contents increase or decrease from the optimum value, soil structure will loosen and deteriorate the mechanical properties. In addition, the increase in water content has quite different effects on strength properties of gravelly soils with different FCs in a triaxial test due to the opposite effects of pore water softening and negative pore pressure strengthening. Such results are expected to provide guidance for the preparation of gravelly soils in engineering practices.

\section{Introduction}

Gravelly soil is a kind of coarse-grained soil that has relatively excellent physical and mechanical properties. It is widely adopted as a kind of civil and construction material in railway engineering, highway engineering, hydraulic dam engineering, and so on. For example, graded gravel, as a kind of gravelly soil, is ordinarily used to fill the surface layer of subgrade bed for high-speed railways in Japan, Germany, France, Spain, and China [1]. As the uppermost layer of the geotechnical substructure, the surface layer of subgrade bed suffers both the static load of track structure and the dynamic load of high-speed train. Therefore, the gravelly fillings in surface layer should be mixed with each other properly to possess favorable grading properties that enable the fillings to obtain the densely compacted structure. Moreover, a dam project also universally uses gravelly soils to fill with the core wall. In the similar way, the grading curve of the gravelly fillings is also required to be designed reasonably [2]. Besides, gravelly soils are also generated and reused in backfill projects extensively in mountainous regions and coastal areas due to the severe shortage of land resources, and their compaction characteristics and strength properties are also emphasized in the backfill engineering practices [3]. Although gravelly soils are widely adopted as construction materials in civil engineering, their mechanical properties are uncertain and susceptible to grading properties, void distribution features, origin of the fine particles, fine contents, and so on.

When adopted in a certain engineering project, gravelly soils are generally required to be compacted properly to obtain enough bearing compacity. Therefore, compaction characteristics and strength properties of gravelly soils are necessarily emphasized. Mikuni and Asao [4, 5] investigate 
the compaction characteristics of gravelly soils that are used to fill a rockfill dam termed as Miboro Dam with a crest height of $131 \mathrm{~m}$. They pointed out that the maximum dry density $\rho_{d \max }$ is remarkably increased with compaction energy, while optimum water content $w_{\text {opt }}$ decreases gradually with the increase in compaction energy. With the compaction data of Miboro Dam fillings, Tatsuoka [6] proposed that the relationship between dry density $\rho_{d}$ and saturation degree $S_{r}$ should be established, and in the same way, the optimum saturation degree $S_{\text {ropt }}$ can be obtained for a given gravelly soil compacted under a given energy level. Besides, Tatsuoka and Gomes Correia [7] further reported that the compaction curves of the gravelly soils can be normalized into a unique line which is independent of compaction energy level by plotting $\rho_{d} / \rho_{d \max }$ against $S_{r}-S_{\text {ropt }}$. Matsumura and Tatsuoka [8] obtained the horizontal slice images by X-ray CT scanning for K3 soil with a compaction coefficient of $100 \%$ at different water contents to analyze the effect of water content on soil structure properties after compaction. The compaction characteristics of the soils greatly influence the strength and stiffness properties of the corresponding samples. Nowak and Gilbert [9] considered that the saturation degree $S_{r}$ should be controlled to equal to $S_{\text {ropt }}$ to obtain the maximum strength or stiffness after wetting under given compaction conditions. Furthermore, it is noted by Tatsuoka and Gomes Correia [7] that unsoaked CBR of the compacted soil is closely linked with $S_{r}$ and $\rho_{d}$, and the empirical relationship is established to evaluate unsoaked CBR with $S_{r}$ and $\rho_{d}$ known. $\mathrm{Ng}$ et al. emphasized that unsaturated suction-dependent soil stiffness should be taken into consideration in the deep excavation engineering, which implies that saturation degree $S_{r}$ could significantly influence the mechanical behaviors of soil structures [10]. By preparing gravelly soils with different fine contents and compacting them at different water contents, Jenkins [11] proposed that the undrained shear strength of gravelly soil in a UU triaxial test is uniquely related with unsoaked CBR value irrespective of soil type and compacted states. It thus can be deduced that the undrained shear strength is also notably influenced by the compaction characteristics.

Actually, the mechanical behaviors of coarse-grained soils are determined by various factors, such as moisture content, grain gradation, fine content, origin of soil particles, and crushing effect [12-17]. Cao et al. [12] conducted a largescale triaxial test on crushed tuff gravelly soils under optimum moisture condition and saturated condition. Results show that axial strain accumulation is aggravated and resilient modulus is reduced under cyclic loadings by the increase in moisture content from optimum to saturated condition. Several series of large-scale cyclic triaxial tests were conducted on unbounded granular materials to investigate the effects of grain gradation on plastic strain accumulation. It is found that the granular material with uniformity coefficient $C_{u}=22.8$ has the distinctly smallest axial strain and volumetric strain, followed by granular material with $C_{u}=19.6$ and material with $C_{u}=6.1$ [13]. Chen et al. noted that larger grains in gravelly soils can be crushed into smaller grains under compression or shear stress, resulting in the variation in grain size, grain shape, grain location, arrangement, and contact features [3]. These variations due to crushing effect will notably influence the deformability and strength properties of gravelly soils. Moreover, the influences of stress and soil compaction on the soil water retention curves are investigated for granite soil, and furthermore, its implications for subgrade ground settlement are discussed in detail [18].

Among the factors that could influence the mechanical properties of coarse-grained soils, fine content is greatly emphasized [19-25]. Babić [19] mixed two types of fine particles of stone and clay origin, respectively, with granular stone material to study the effect of fine particles on bearing capacity of granular base course. Results show that fine clay particles should be less than $5 \%$ by mass since bearing capacity decreases for higher fine percentages. However, bearing capacity has a positive relationship with fine stone contents within the scope of 0 to $10 \%$ by mass. Computed tomography scan and large-scale triaxial test were performed by Cao et al. [20] to investigate long-term behavior of clay-fouled granular materials. It is found that the invasion of fines into the granular materials changes the internal soil structure remarkably, and consequently, the dominant effect of fines transit from lubrication to densification and then to suffocation as fine contents increase. Chen and Zhang [21] also evidenced that fine clay invasion of subgrade soils into unbound aggregate subbase will lead to the decrease in peak strength and critical strength, with a $20 \%-30 \%$ strength loss. In addition, the triaxial test was performed by Ekblad and Isacsson [22] to discuss the influence of mica content on mechanical properties of coarse granular materials. They found that resilient modulus and stiffness decreased obviously with increased mica content. Duong et al. [23] performed a large-scale cyclic triaxial test on interlayer soil of railway substructure at three water contents and three fine contents, respectively, to investigate the resilient behavior. They found that the soils having high fine contents show higher resilient modulus due to the suction effect under unsaturated conditions. Nevertheless, the fine contents could generate negative effect on the resilient modulus as the soil approaches the saturated conditions. Cui [24] reported that the soil structure is determined by the coarse grains portion in coarse grain/fines mixture through $\mathrm{X}$-ray $\mu \mathrm{CT}$ scan. When volumetric content of coarse grains $f_{v}$ varies from $0 \%$ to $10 \%$, the fines establish the skeleton of the sample; when $f_{v}$ reaches $20 \%$, the connections between coarse grains start to develop; as $f_{v}>35 \%$, almost all coarse grains participate in the establishment of the skeleton with grain-grain contacts. Similarly, Jehring Bareither [25] also proposed that the mechanical behavior of the mixtures containing waste rock (a kind of crushed gravel) and tailings is determined by proportions of each ingredient. Besides, the liquefaction resistance of the coarse-grained soils is also remarkably influenced by the fine contents [26-28].

As could be seen from the abovementioned literatures, mechanical properties of gravelly soils are susceptible to various factors, among which fine content (FC) is worth particular attention. However, many of the previous studies 
mainly discuss either compaction behaviors or strength properties, and the description about the relationship between these two mechanical characteristics is relatively few. Furthermore, the influence mechanism of FC on the mechanical behaviors of coarse-grained soils was investigated regardless of the variation in moisture content in many previous cases, which could not systematically reflect the different development features of mechanical behaviors under different water contents for soils with various FCs. In this study, compaction characteristics and strength properties of gravelly soils are closely linked to discuss the mechanical behaviors and soil structures of gravelly soils, and the influence mechanism of FC is analyzed quantitatively. Besides, interaction of fine content and water content is discussed in detail for gravelly soils to reveal the different variation laws of mechanical behaviors with water contents for soils with different FCs. The results are expected to provide technical guidance for the preparation of gravelly soils that is intended to be adopted in engineering practice.

\section{Materials and Methods}

2.1. Test Materials. Graded gravel, as a kind of gravelly soil, is selected as the tested material in this study. The gravel samples are mechanically disrupted from pebbles and boulders to form particles with different shapes and sizes. Their source rocks are granite mingled with quartz stone or quartz sandstone. According to TB 10621-2014 [1], the tested graded gravels are suitable to be adopted to fill the surface layer of subgrade bed in a high-speed railway construction work.

After taken to the laboratory, gravel samples are carefully hand-washed by tap water to remove the fine-grained fraction. After washing, the samples are air-dried for 12 hours, and then, pure graded gravels are obtained. After that, the pure gravel is sieved by a square hole sieve to obtain its grain size distribution, as shown by Figure 1(a). It can be seen that all the particles have grain sizes ranging from $0.075 \mathrm{~mm}$ to $30 \mathrm{~mm}$ after washing. In other words, no fine particle is existed in the gravel mass. On the contrary, fine-grained particles (with grain size $<0.075 \mathrm{~mm}$ ) are also prepared to mix with pure graded gravels to investigate the influence of finegrain content on compaction properties and strength characteristics. The fine particles are composed of $91.8 \%$ silt and $8.2 \%$ clay fraction. Grain size distribution of the fine-grained soil is plotted independently, as shown in Figure 1(b).

The tested gravel samples are divided into five groups with equal mass, and different contents of fine-grained soil are mixed with each group of pure graded gravels to prepare gravel samples that have fine contents of $5 \%, 10 \%, 20 \%, 30 \%$, $40 \%$, and $50 \%$, respectively. After mixing, each group of mixture is placed in an airtight cylindrical container that has sufficient excessive volume to turn upside down for ten times to make fine-grained particles distribute evenly in the gravel mass. Then, preparation of graded gravels with different fine-grain contents is accomplished.

2.2. Test Apparatus. Compaction test and triaxial test apparatus are used in this test program. Proctor compaction test apparatus is designed and manufactured by Shiji
Chengda Instruments, Ltd., as shown in Figure 2(a). The Proctor cylinder has a volume of $2103.9 \mathrm{~cm}^{3}$, with $152 \mathrm{~mm}$ in diameter and $116 \mathrm{~mm}$ in length. According to ASTM D 1557-09 and GB T 50123-2019 [29, 30], a drop hammer that weighs $4.5 \mathrm{~kg}$ is selected to perform the modified Proctor compaction test. During compaction, the hammer is dropped from a height of $457 \mathrm{~mm}$ every time to compact the graded gravels in the Proctor cylinder.

The working mechanism of compaction apparatus is shown in Figures 2(b) and 2(c). In every compaction cycle, a gear that is driven by servo motor rotates clockwise to lift a vertical spline with a drop hammer attached to one end. In the lifting process, the gear teeth and spline teeth occlude with each other all along. When a height of $457 \mathrm{~mm}$ is reached for the hammer, the gear path is just accomplished. The gear teeth and spline teeth separate with each other, and the hammer, along with the vertical spline, starts to drop down to compact the gravel samples. In the next compaction cycle, the gear and spline occlude with each other again to start the next lifting and dropping.

Different hammer drops have different drop points, as shown in Figure 2(c). Initial eight hammer drops distribute along the inner side wall of the compaction cylinder. After each dropping and lifting cycle, the Proctor cylindrical container rotates anticlockwise for $45^{\circ}$ to accommodate the next dropping. Remarkably, overlapped area that is compacted repeatedly existed in the two adjacent dropping points. At the same time, some dead zones are also presented along the margin of the side wall. After the eighth drop accomplished, the compaction container moves horizontally for a suitable distance, while the anticlockwise rotation takes place, accommodating the ninth drop whose point locates in the center of container. Although some overlapped areas and dead zones are presented in this compaction scheme, uniform settlement can be obtained across the whole section of the cylinder.

The triaxial test apparatus used in this study is designed and manufactured by GDS Instruments, Ltd. The apparatus is composed of actuating device to apply vertical load, pressure controller to provide confining and backpressure, triaxial cell to accommodate specimen, transducers to collect deformation and pore pressure data, plastic tube to drain water or air, and computer to process data, as shown in Figure 3. The pressure controller is connected with triaxial cell with a plastic tube. In the testing process, pressure controller drives deaired water into the cell or specimen to provide confining pressure or backpressure. The controllers can provide the largest confining pressure of $2 \mathrm{MPa}$ and the greatest backpressure of $1 \mathrm{MPa}$. At the same time, load, displacement, and pore pressure transducers can collect data automatically to feedback to the computer. This triaxial apparatus is suitable to perform tests for samples whose diameter is less than $100 \mathrm{~mm}$.

However, the maximum particle diameter of the tested graded gravel is $30 \mathrm{~mm}$. According to GB T 50123-2019 [30], a gravel sample with a diameter of at least $150 \mathrm{~mm}$ is needed to perform a triaxial test to avoid boundary effect on the test results. For this purpose, a large load cell is designed to accommodate the $150 \mathrm{~mm}$-diameter sample. Moreover, 


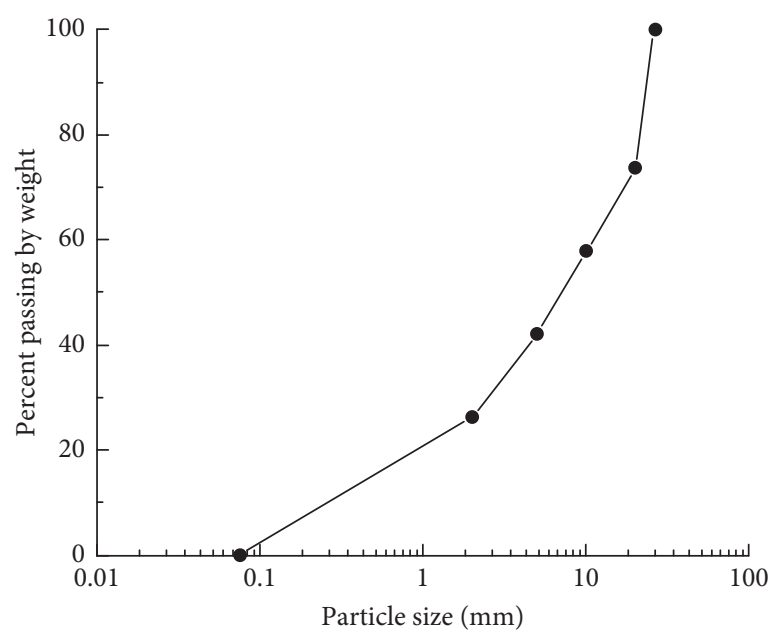

(a)

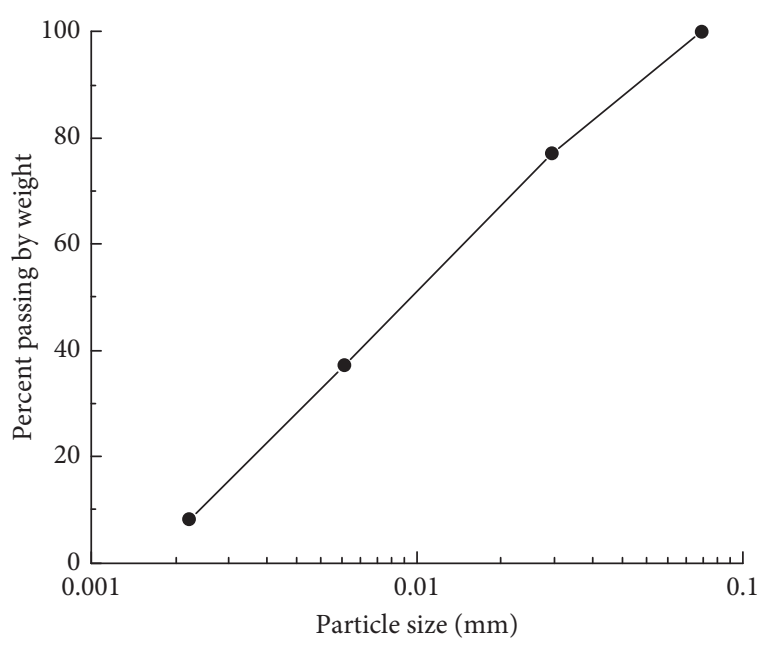

(b)

FIGURE 1: Grain size distribution for (a) coarse-grained portion and (b) fine-grained portion.

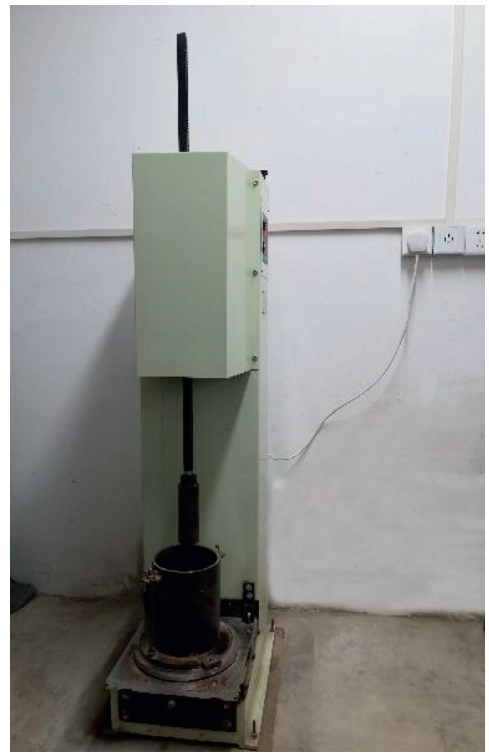

(a)

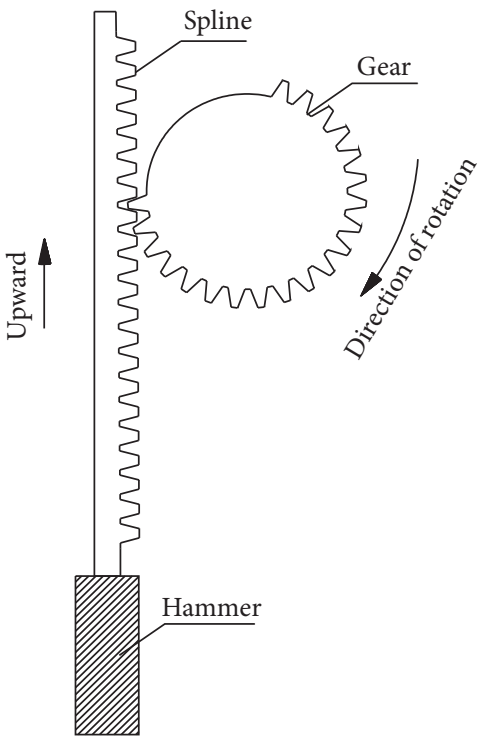

(b)

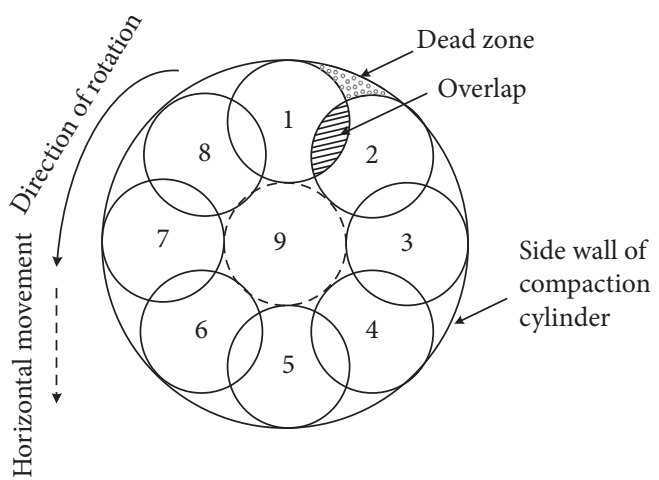

(c)

FIgURE 2: Compaction apparatus adopted in this study: (a) pictures of apparatus; (b) lifting mechanism of drop hammer; (c) drop locations.

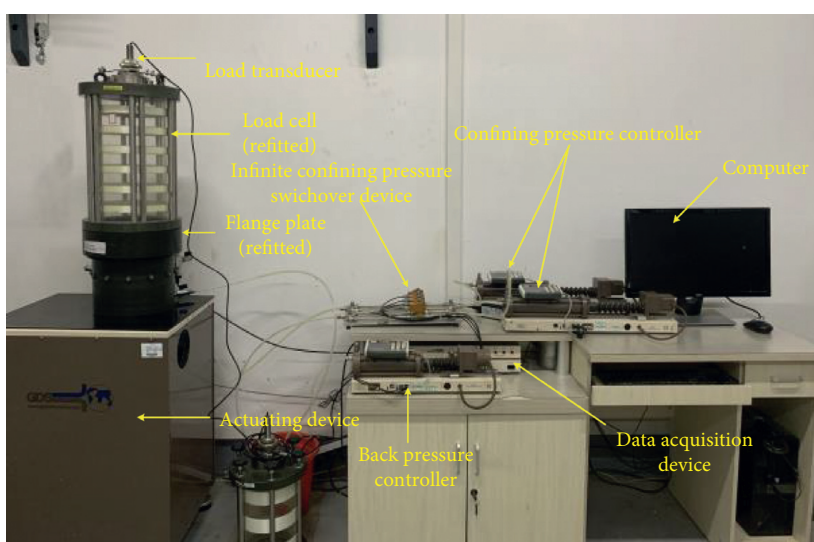

(a)

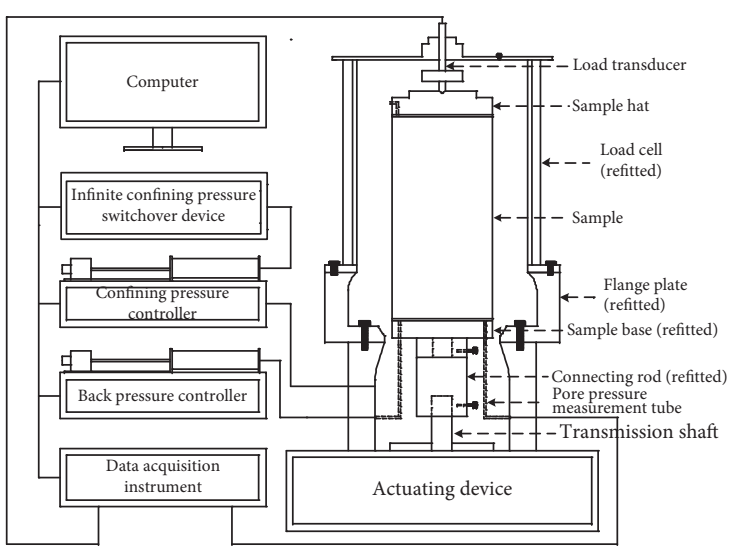

(b)

Figure 3: GDS triaxial test apparatus in (a) photo and (b) diagram. 
refitted flange plate, pedestal, and connecting rod are also prepared to support the large load cell, as shown in Figure 4(a). As the refitted large load cell needs more water supply to sustain a constant confining pressure in the consolidation process compared with the original cell, a single confining pressure controller is not sufficient to provide plentiful pressure water since the cubage of a single controller is only $200 \mathrm{ml}$. With this deficiency in mind, an infinite confining pressure switchover device is adopted to supply sufficient pressure water. The switchover device is connected with two confining pressure controllers on the one side. However, on the other side, the two water outlets on the device are linked with a load cell and a water source, respectively, as shown in Figure 4(b). In the consolidation process, confining pressure controller I is firstly activated to supply pressure water to the load cell to impose confining pressure on the gravel sample. Once pressure water in controller I is exhausted, the switchover device is cut automatically to activate confining pressure controller II to supply pressure water. At the same time, controller I is unblocked to the water source via a switchover device to replenish water into the controller. When controller II is exhausted, controller I is activated again. The two confining pressure controllers are activated alternatively to supply water until the pressure water in load cell is sufficient to provide constant confining pressure. In this way, confining pressure in the large-sized load cell can be kept constant.

2.3. Test Method. All of the graded gravel samples with fine contents of $5 \%, 10 \%, 20 \%, 30 \%, 40 \%$, and $50 \%$ were prepared to perform a compaction test. The gravel with a certain amount of fine content was divided into six equivalent groups. Tap water was added to each group of gravels to prepare samples with targeted water contents of $2 \%, 4 \%, 6 \%$, $8 \%, 10 \%$, and $12 \%$.

In the compaction process, gravel samples with different water contents were filled into the Proctor compaction container by three layers. After each layer of gravel sample was filled, the hammer dropped from a height of $457 \mathrm{~mm}$ and compacted the layer for 94 times. Then, the next layer was filled and compacted for another 94 times. A sample was compacted for 282 times totally in a compaction test, and the compaction energy was $2701 \mathrm{~kJ} \cdot \mathrm{m} / \mathrm{m}^{3}$. After compaction, the sample in the container was weighed to calculate its natural density. Then, gravels that weigh $300 \mathrm{~g}$ were collected from the sample to measure its water content. At last, the dry density can be evaluated for the gravel samples with different water contents.

Given the fact that fine content of surface layer fillings of subgrade bed for high-speed railway is generally less than $20 \%$, and graded gravel samples with fine contents of $5 \%$, $10 \%$, and $20 \%$ were prepared for the triaxial test. The triaxial sample was $150 \mathrm{~mm}$ in diameter and $300 \mathrm{~mm}$ in height. Both kinds of samples, in optimum water content state and in saturated state, were needed to perform the triaxial test. To prepare the sample, suitable amount of water was added into the gravel sample to obtain the optimum water content state initially. Then, a moderate number of gravels were weighed to prepare the triaxial sample that has a compaction coefficient of 0.97. After that, the weighed gravels were divided into five equivalent portions to fill the model container by five layers. After each layer was filled, it was compacted slightly to a thickness of $60 \mathrm{~mm}$. After the fifth layer was filled and compacted, the gravel sample in optimum water content was prepared to perform the triaxial test. Since the bottom layers suffer more compaction energy than the top layers, this sample preparation method inevitably causes the dry density to be nonuniform over the structural height [31]. However, this preparation error can be neglected since the effect is the same to all the gravel samples [12].

However, preparation of the saturated gravel sample still needs the saturation process. After filling and compaction, the gravel sample in optimum water content was moved to the vacuum saturation cylinder to start the saturation process. The vacuum saturation cylinder was set to one negative atmosphere pressure. At the same time, deaired water was injected into the saturation cylinder, while air exhaustion was conducted simultaneously. When the gravel sample was submerged into the deaired water, water injection and air exhaustion were accomplished. Then, the sample was left standing for $12 \mathrm{~h}$ to saturate under the effect of atmosphere pressure. After vacuum saturation, the sample was moved to the GDS triaxial apparatus to measure its pore pressure coefficient $B$. If $B$ goes beyond 0.95 , the sample can be regarded as saturated. If $B$ is still less than 0.95 , backpressure saturation is necessary to be conducted until the value of $B$ goes beyond 0.95 . In a backpressure saturation process, the backpressure increment is set as $30 \mathrm{kPa}$ for each stage.

\section{Test Results}

3.1. Compaction Test Results. The compaction curves of graded gravel samples with different FCs are shown in Figure 5. The gravel sample with 5\% FCs is denoted as 5\% FC in the figure. The denotations of gravel samples with other magnitudes of FCs remain the same. The asymptotic compaction lines under the condition that both specific gravity $G_{s}$ and saturation degree $S_{r}$ are given can be deduced from the three-phase relationship of the soil, as shown by the following equation:

$$
\rho_{d}=\frac{G_{s}}{\left(w G_{s} / S_{r} \rho_{w}\right)+1},
$$

where $\rho_{d}$ is the dry density of gravel sample, $w$ is the water content, and $\rho_{w}$ is the density of pure water. The theoretical compression lines are also plotted in Figure 5 as references. It is indicated that all of the gravel samples have an optimum water content $w_{\text {opt }}$ that is corresponding to the maximum dry density $\rho_{d \max }$. The dry density $\rho_{d}$ increases with water content $w$ on the condition of $w<w_{\text {opt }}$ but decreases with the increase in water content on the condition of $w>w_{\text {opt }}$. As water content increases to a certain extent, the measured compression curves of the gravel samples are very close to the theoretical compaction line that corresponds to $S_{r}=100 \%$, indicating that the gavel samples with high water contents are close to saturation after compaction. In addition, it is worth noting that the measured water content after 


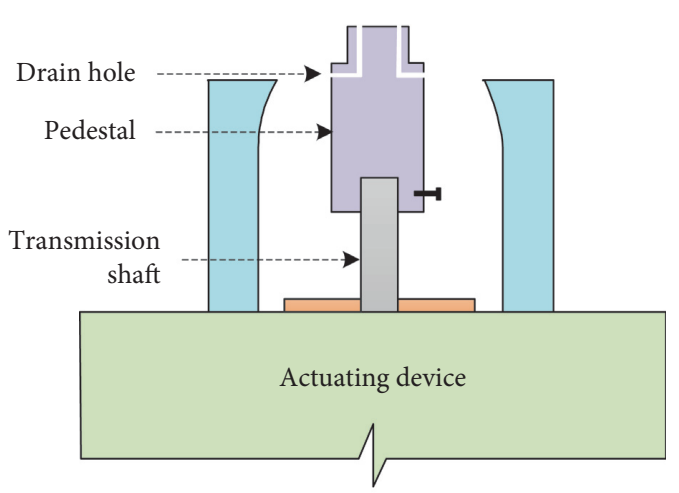

Before refitting

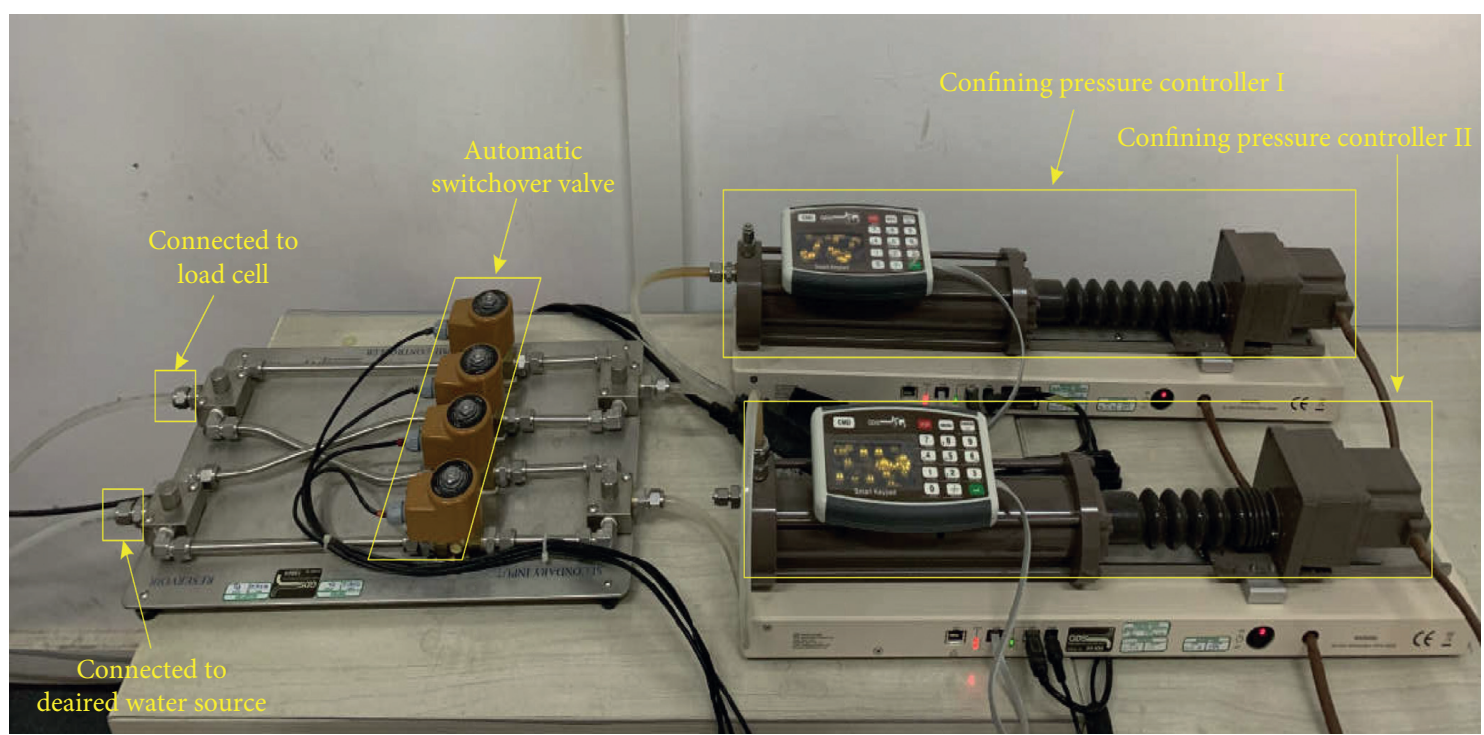

(b)

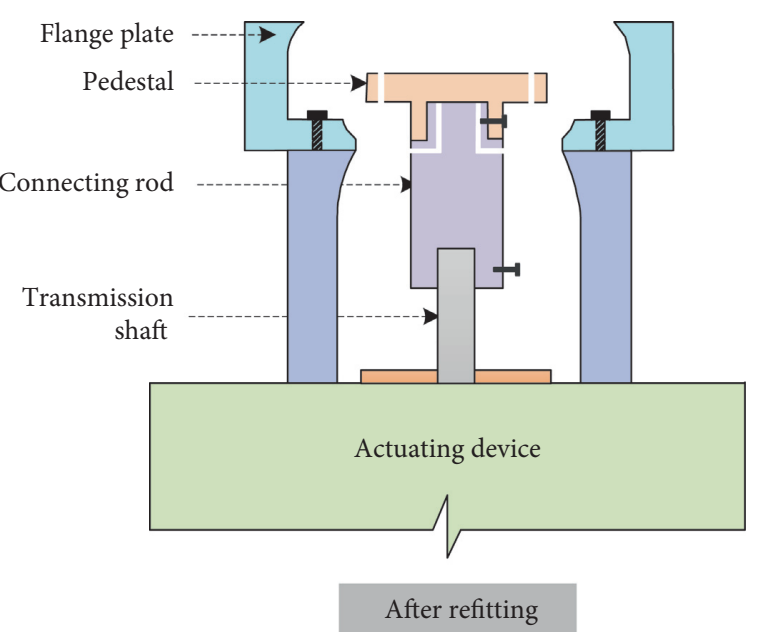

(a)

FIGURE 4: Refitting scheme of GDS triaxial apparatus for (a) pedestal and flange plate to support large load cell and (b) infinite confining pressure switchover device to supply sufficient pressure water.

compaction is significantly less than the targeted water content for the gravel samples with lower FCs. As FC increases, water holding capacity of the gravel sample also rises.

Moreover, 10\% FC gravel sample tends to have the largest $\rho_{d \max }$ and the minimum $w_{\text {opt }}$ compared with gravel samples with other magnitudes of FCs. 5\% FC gravel sample has $\rho_{d \max }$ that is similar to $20 \% \mathrm{FC}$ sample. The maximum dry density $\rho_{d \max }$ of $5 \%$ FC and $20 \%$ FC samples is just lower than that of $10 \%$ FC sample but is remarkably higher than those of $30 \%$ FC, $40 \%$ FC, and 50\% FC samples. Actually, when fine content goes beyond $20 \%, \rho_{d \max }$ decreases remarkably with the increase in FC. Moreover, it is interesting to find that the coordinate point corresponding the optimum water content $w_{\text {opt }}$ and maximum dry density $\rho_{d \max }$, which can be denoted as $\left(w_{\mathrm{opt}}, \rho_{d \max }\right)$, shows different characteristics for gravel samples with different FCs. The coordinate point $\left(w_{\mathrm{opt}}, \rho_{d \max }\right)$ of $10 \% \mathrm{FC}$ gravel samples locates within the scope between asymptotic compaction lines determined by the condition of $S_{r}=100 \%$ and $S_{r}=90 \%$, demonstrating that saturation degree is higher than $90 \%$ for the $10 \%$ FC sample when $\rho_{d \max }$ is obtained. Furthermore, the featured points of 5\% FC, $20 \%$ FC, and 30\% FC samples lie between the theoretical compaction lines plotted on a basis of $S_{r}=90 \%$ and $S_{r}=80 \%$. This implies that the saturation degree corresponding to $\rho_{d \max }$ (termed as optimum saturation degree and denoted as $S_{\text {ropt }}$ hereinafter) remains between $80 \%$ and $90 \%$. $S_{\text {ropt }}$ is slightly lower than $80 \%$ for the gravel samples whose fine contents are $40 \%$ and $50 \%$, respectively.

Saturation degree $S_{r}$ of the gravel sample can be precisely calculated with $w$ and $\rho_{d}$ known, as shown by the following equation:

$$
S_{r}=\frac{w G_{s}}{\left(\left(G_{s} / \rho_{d}\right)-1\right) \rho_{w}}
$$




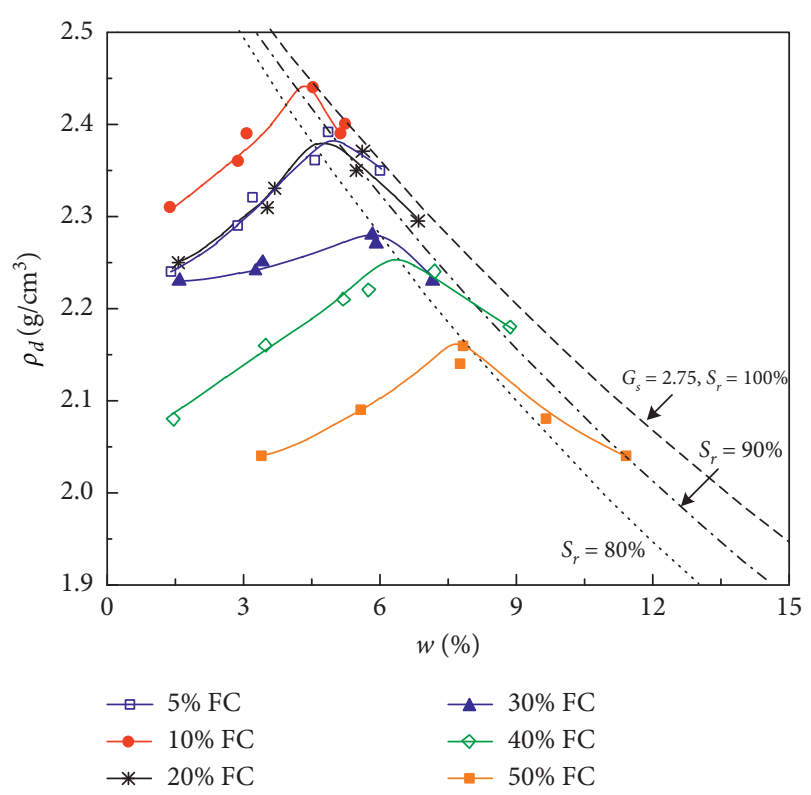

FIGURE 5: Compaction curves for gravel samples with different fine contents.

Therefore, the relationship between dry density $\rho_{d}$ and saturation degree $S_{r}$ can be established, as shown in Figure 6(a). Remarkably, the 10\% FC sample has the largest optimum saturation degree $S_{\text {ropt }}$ compared with gravel samples with other magnitudes of FCs. When FC goes beyond $20 \%$, there is an obvious decreasing trend for $S_{\text {ropt }}$ with the increased FC. Furthermore, compaction coefficient, which is calculated as $\rho_{d} / \rho_{d \max }$, can be plotted against $S_{r}-S_{\text {ropt }}$ for gravel samples with different FCs to obtain a unique normalized curve, as reported by Tatsuoka and Correia [7] and shown in Figure 6(b). It should be noted that $\rho_{d \max }$ and $S_{\text {ropt }}$ are two critical parameters that are significantly influenced by FC of graded gravel samples. With $\rho_{d}$ normalized by $\rho_{d \max }$ and $S_{r}$ normalized by $S_{\text {ropt }}$, graded gravels with different FCs present similar compaction behaviors that are unsusceptible to FCs.

3.2. Triaxial Test Results. Gravel samples with FCs ranging from $5 \%$ to $20 \%$ are adopted to perform the triaxial test. The deviatoric stress is plotted against axial strain to demonstrate the strength and deformation properties for graded gravels under saturation water content (SWC) and optimum water content (OWC) conditions, as shown in Figure 7. As shown in Figure 7(a), the deviatoric stress increases with axial strain initially for gravel samples with $5 \%, 10 \%$, and $20 \%$ FCs on the condition that confining pressure $\sigma_{3}$ is $20 \mathrm{kPa}$. As the deviatoric stress reaches its peak value, it will decrease with the increase in axial strain until the deviatoric stress levels off to its residual value. Thus, graded gravels with different FCs present strain softening characteristics under SWC and OWC conditions when $\sigma_{3}=20 \mathrm{kPa}$. However, SWC samples demonstrate weaker strain softening degree compared with OWC samples. This phenomenon can be due to the larger magnitude of negative pore pressure of SWC samples in the shearing process compared to OWC samples, as shown in
Figure $8(a)$. Negative pore pressure in the shearing process aids in improving effective confining pressure, which further promotes the strength properties and weakens the softening properties of the gravel samples. On the contrary, the stronger strain softening presented in OWC samples may also attribute to the suction-induced dilatancy in the unsaturated OWC samples [32]. Take the 10\% FC gravel sample; for example, the matric suction in the unsaturated OWC sample increases the peak strength owing to a reduction in water content compared with SWC samples, but the dilatancy can also lead to a decrease in dry density for the OWC sample, which will reduce the residual deviatoric stress, resulting in a significant strain softening behavior.

More importantly, 10\% FC gravel samples have the maximum peak strength regardless of the water content. Meanwhile, the peak strength of $10 \% \mathrm{FC}$ sample is $630 \mathrm{kPa}$ on the condition of OWC, and its peak strength decreases to $520 \mathrm{kPa}$ after saturation. However, the peak strengths of 5\% and $20 \% \mathrm{FC}$ samples are $280 \mathrm{kPa}$ and $320 \mathrm{kPa}$, respectively, under OWC condition. It is interesting to find that their strengths unexpectedly increase to $380 \mathrm{kPa}$ and $340 \mathrm{kPa}$, respectively, when they are saturated.

Gravel samples with different water contents also present strain softening properties on the conditions that the confining stresses are $40 \mathrm{kPa}$ and $60 \mathrm{kPa}$, respectively, as shown in Figures 7(b) and 7(c). Also, the softening degree weakens after saturation for the gravel samples with different FCs when $\sigma_{3}=40 \mathrm{kPa}$ and $\sigma_{3}=60 \mathrm{kPa}$. Furthermore, $10 \% \mathrm{FC}$ samples also have the maximum peak stresses compared with other samples. By comparing Figures $7(\mathrm{a})-7(\mathrm{c})$, it is remarkable that the peak strength increases with confining pressure for gravel sample with a given FC under a given moisture condition. For example, the $20 \%$ FC gravel sample has a peak strength of $320 \mathrm{kPa}$ under OWC condition when $\sigma_{3}=20 \mathrm{kPa}$, and its strength increases to $430 \mathrm{kPa}$ and $590 \mathrm{kPa}$ when the confining pressure rises to $40 \mathrm{kPa}$ and $60 \mathrm{kPa}$, respectively.

Besides, although gravel samples have different magnitudes of peak strengths that vary with FC and confining pressure, the axial strain corresponding to the peak strength (termed as featured axial strain hereinafter) remains close to $2 \%$ for all the gravel samples on the condition of OWC. However, once gravel samples are saturated, the featured axial strain differs with FC significantly. All of the featured axial strains under the three levels of confining pressures are larger than $2 \%$ for $10 \%$ FC sample, averaging at 3.1\%. Nevertheless, the 5\% FC sample and 20\% FC sample only have average featured axial strains of $2 \%$ and $1.1 \%$, respectively. This indicates that the featured axial strain of $10 \%$ FC sample increases remarkably when the moisture condition changes from OWC to SWC, while the featured axial strains of $5 \%$ and $20 \%$ FC samples level off or decrease after saturation. It implies that the $10 \% \mathrm{FC}$ sample presents stronger deformation resistance compared with gravel samples with other magnitudes of fine contents after saturation.

Figure 8 shows the pore pressure evolvement characteristics against axial strain for graded gravels with different FCs. It should be noted that the pore pressure in the OWC 


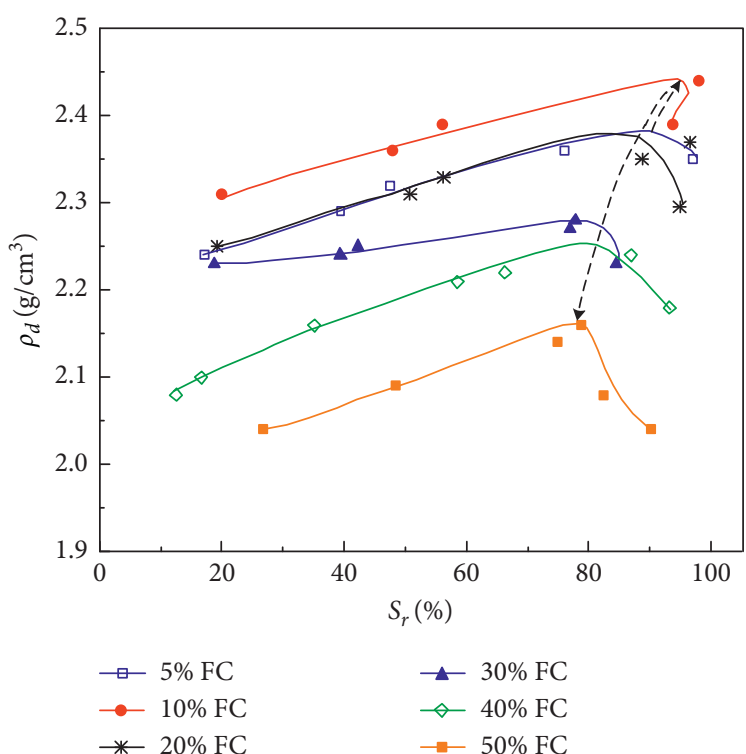

(a)

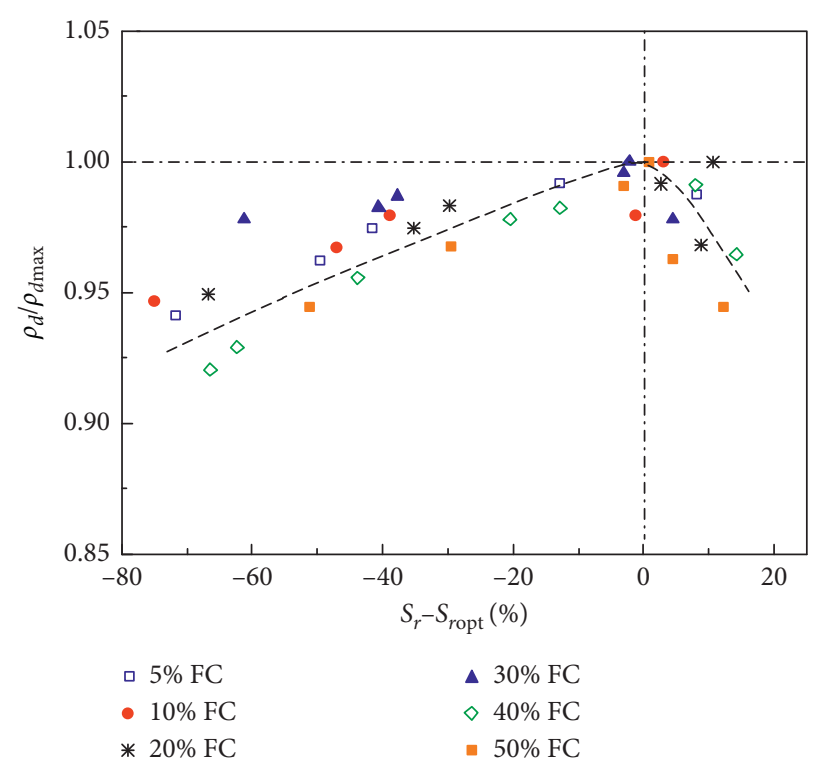

(b)

FIGURE 6: Compaction curves plotted in terms of saturation degree: (a) dry density $\rho_{d}$ plotted against saturation degree $S_{r}$; (b) $\rho_{d} / \rho_{d \text { max }}$ against $S_{r}-S_{\text {ropt }}$.

samples not only include pore water pressure but also contain pore air pressure since the OWC samples remain unsaturated state. The overall pore pressure was monitored for the OWC samples to demonstrate the variation in effective stress state in the shearing process. The pore pressure increases slightly with axial strain in the initial period for the gravel samples with different FCs on the condition of $\sigma_{3}=20 \mathrm{kPa}$. However, it decreases to zero and further becomes negative pore pressure rapidly. As axial strain increases, the negative pore pressure develops continuously until it levels off to a certain value. This can be attributed to the fact that the total volume of gravel sample decreases slightly in the preliminary stage, resulting in the increase in pore pressure initially. Since the gravel sample is densely compacted in the preparation stage, its volume tends to increase with axial strain in the subsequent shearing stage. The dilating sample will undoubtedly lead to continuous development of negative pore pressure. Of course, negative pore pressure levels off at the later period due to the gradually stable sample volume until the gravel sample collapses. Besides, negative pore pressure in the SWC samples is universally larger than the OWC samples on the condition that FC is given. This is because pore water is more difficult to be compressed than pore air, leading to the larger negative pore pressure accumulated in the SWC samples during the shearing process. The evolvement characteristics of pore pressure on the condition of $\sigma_{3}=40 \mathrm{kPa}$ and $\sigma_{3}=60 \mathrm{kPa}$ remain the same as those when $\sigma_{3}=20 \mathrm{kPa}$. Moreover, SWC samples also have negative pore pressures that are larger than OWC samples when the confining pressure is $40 \mathrm{kPa}$ and $60 \mathrm{kPa}$, respectively.

More importantly, 10\% FC gravel samples have the maximum negative pore pressure compared to gravel samples with other magnitudes of FC regardless of moisture condition. The accumulated negative pore pressure is closely related to the shear dilatancy of gravel samples. The maximum negative pore pressure presented in 10\% FC gravel sample implies that degree of shear dilatancy in 10\% FC sample is the most significant. At the same time, 10\% FC gravel sample obtains the maximum effective confining pressure due to the maximum negative pore pressure, which contributes to the maximum peak strength in the shearing process to some extent.

\section{Discussion}

4.1. Compaction Characteristics Analysis. The maximum dry density $\rho_{d \max }$ and optimum water content $S_{\text {ropt }}$ are plotted against fine content (FC) to demonstrate compaction characteristics of gravel samples with different FCs, as shown in Figure 9. Notably, FC has a significant effect on $\rho_{d \max }$ and $S_{\text {ropt }}$. When FC $<10 \%, \rho_{d \max }$ and $S_{\text {ropt }}$ tend to increase with FC. However, they begin to decrease continuously with the increase in FC on the condition of FC $>10 \%$. That is to say, $10 \%$ FC samples have the highest $\rho_{d \max }$ and the largest $S_{\text {ropt }}$. Similar results can be found from the compaction test on the five soil types around Miboro Dam site. Grading curves of these five soil types are shown in Figure 10(a). In the same way, fine particles also refer to those whose particle size is less than $0.075 \mathrm{~mm}$. It can be seen that the soils have different FCs ranging from $2.5 \%$ to $37 \%$. Meanwhile, Proctor compaction test was performed on the soils to obtain their compaction properties, as presented in Figure 10(b). All of the compaction curves for the five kinds of soils increase with water content initially but decrease with the increase in water content when water content goes beyond a certain value. Both $\rho_{d \max }$ and $w_{\text {opt }}$ are significantly presented for the five kinds of soils. Interestingly, the $5.7 \%$ FC sample has the 


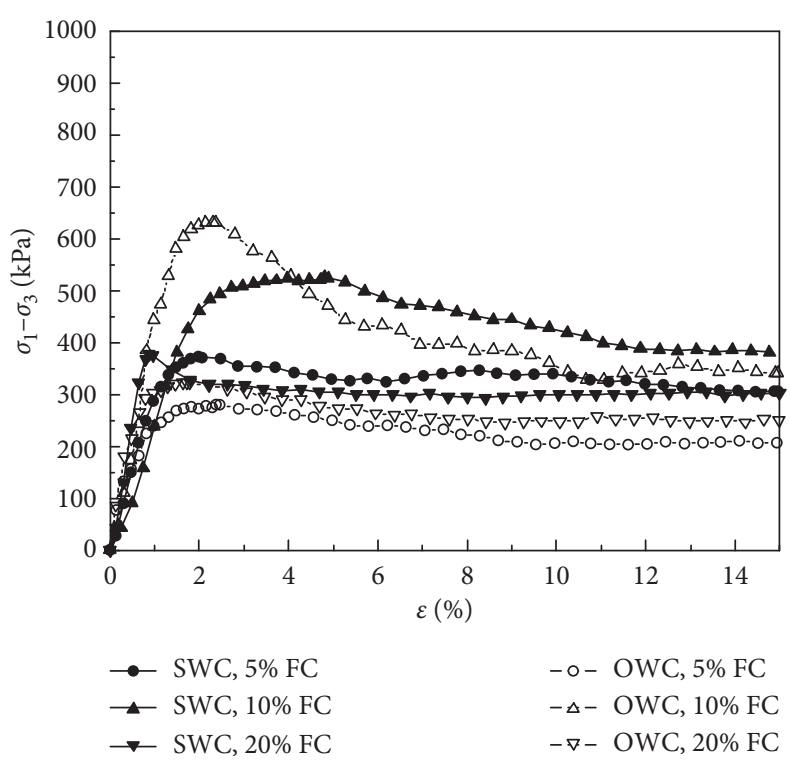

(a)

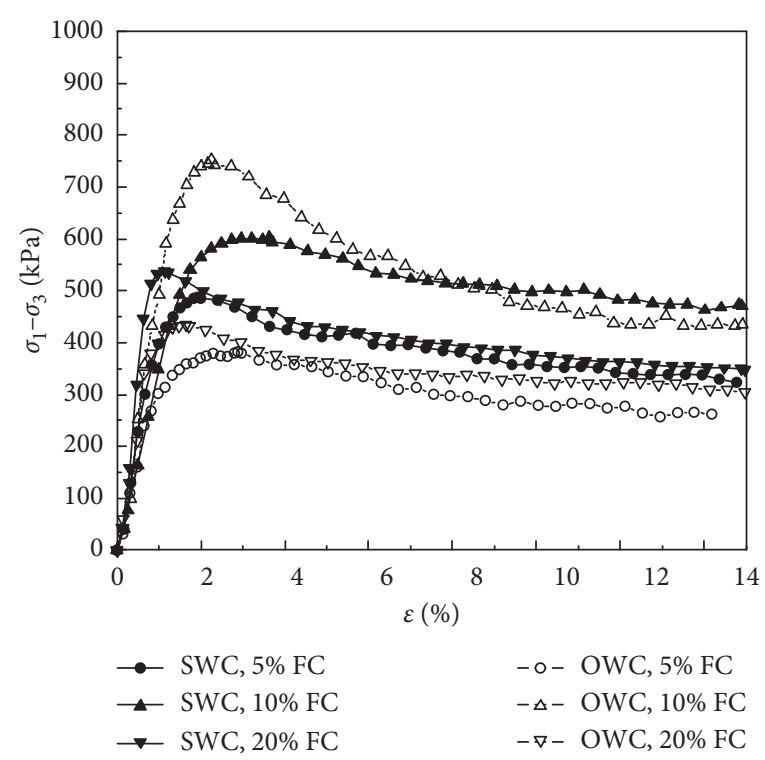

(b)

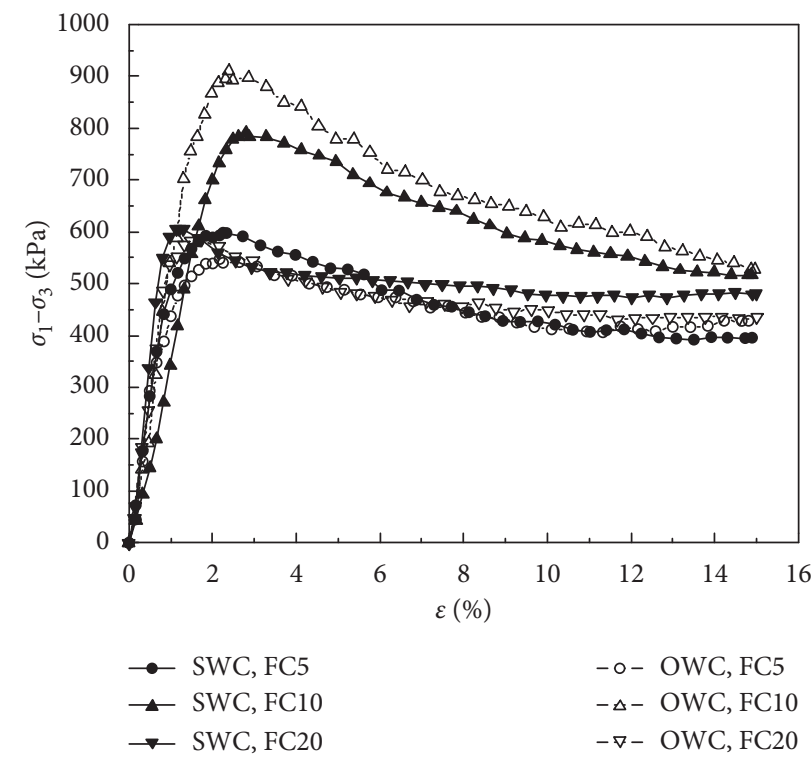

(c)

FIgURE 7: The relationship between deviatoric stress and axial strain for graded gravels under the confining pressure of (a) $20 \mathrm{kPa}$, (b) $40 \mathrm{kPa}$, and (c) $60 \mathrm{kPa}$.

largest $\rho_{d \max }$ and the lowest $w_{\mathrm{opt}}$ compared with soil samples with other magnitudes of FCs. Similarly, the saturation degree $S_{r}$ can also be obtained by equation (2) with $\rho_{d}$ and $w$ known, and the relationship between $\rho_{d}$ and $S_{r}$ of the five kinds of soils is presented in Figure 10(c). It is interesting to find that the $5.7 \%$ FC sample has the maximum $S_{\text {ropt }}$ that equals to $95 \%$. The $S_{\text {ropt }}$ of other samples stays lower than $95 \%$ whenever FC is lower or larger than $5.7 \%$. Thus, the $5.7 \%$ FC soil sample around Miboro Dam site is quite similar to the $10 \%$ FC gravel sample in this study. Both samples tend to possess the densest soil structure in a compaction test compared with samples with other magnitudes of FCs.

Besides, fillings of Miboro Dam also indicate that fine content in coarse-grained soil has a remarkable effect on its compaction properties. Figure 11(a) shows the grading curves of core material used for the field compaction test and sieved material adopted for the laboratory test. The core material has the maximum particle size of $140 \mathrm{~mm}$, while the maximum particle size of sieved material is $4.8 \mathrm{~mm}$. Correspondingly, FC of core material is only $4.1 \%$, comparing with $6.9 \%$ of that of sieved material. Field compaction tests with different compaction energy levels were performed on the core material to obtain its compaction curves, as shown in Figures 11(b) and 11(c). The symbol $N$ denotes the number of compaction roller passes. It indicates that $\rho_{d \max }$ increases from $2.07 \mathrm{~g} / \mathrm{cm}^{3}$ to $2.14 \mathrm{~g} / \mathrm{cm}^{3}$ with compaction energy levels for the core material. On the contrary, $S_{\text {ropt }}$ seems to level off to $86 \%$ under different compaction energy 


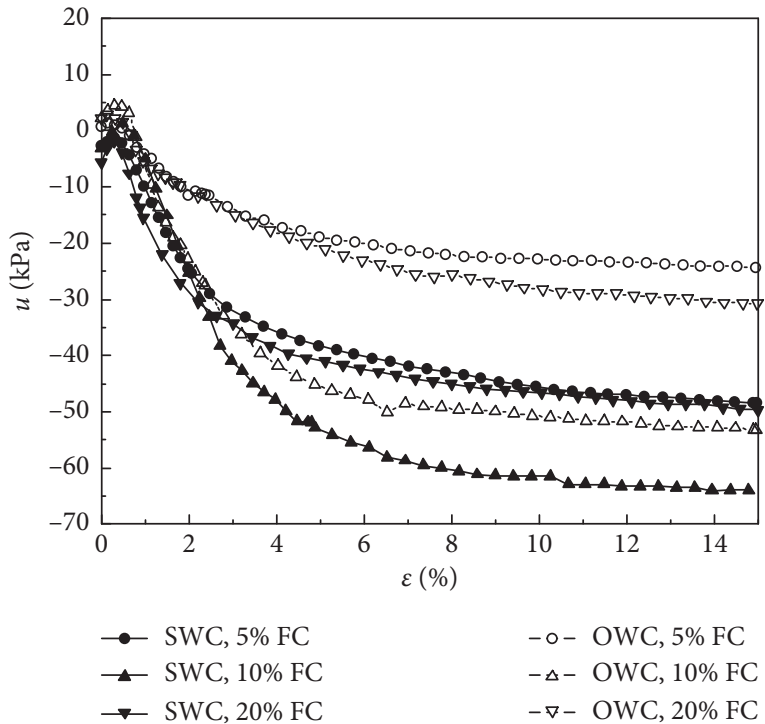

(a)

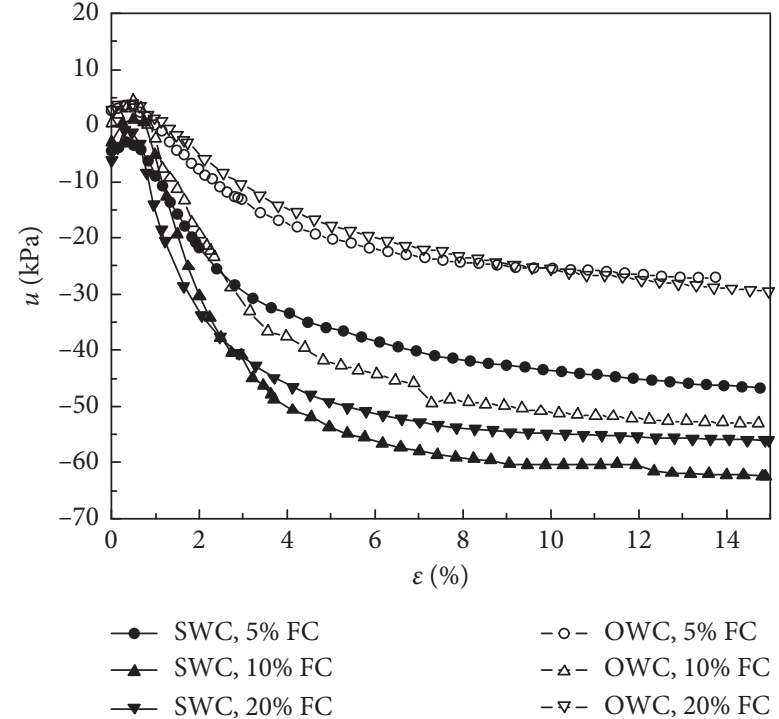

(b)

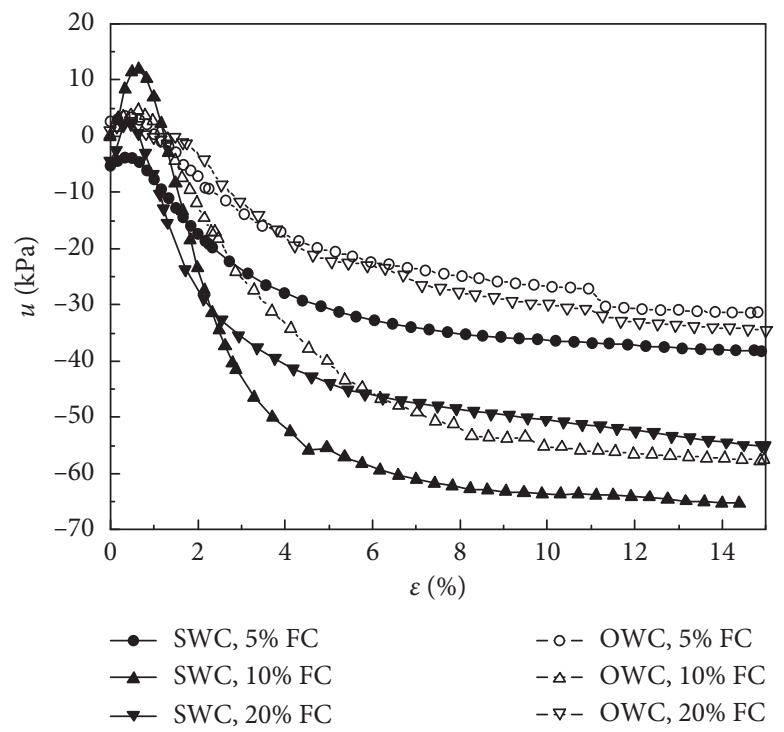

(c)

Figure 8: The evolvement of pore pressure against axial strain for graded gravels under the confining pressure of (a) $20 \mathrm{kPa}$, (b) $40 \mathrm{kPa}$, and (c) $60 \mathrm{kPa}$.

levels. Furthermore, laboratory compaction tests with compaction energy levels ranging from $0.6 \mathrm{Ec}$ to $4.5 \mathrm{Ec}$ were conducted on a sieved material. It is interesting to find that $\rho_{d \max }$ of the sieved material ranges from $1.84 \mathrm{~g} / \mathrm{cm}^{3}$ to $1.98 \mathrm{~g} /$ $\mathrm{cm}^{3}$, as the compaction energy increases from $0.6 \mathrm{Ec}$ to 4.5 Ec. Nevertheless, $S_{\text {ropt }}$ also levels off at $84 \%$ for the laboratory compaction samples, which demonstrates the same development feature as that presented in a field compaction test. However, by comparing compaction curves of core material with that of a sieved material, it can be concluded that $S_{\text {ropt }}$ varies obviously with FCs of the coarsegrained soils.

To further illustrate the compaction properties of the coarse-grained soils with different FCs, the optimum saturation degree $S_{\text {ropt }}$ is plotted against the maximum dry density $\rho_{d \max }$ for the tested graded gravels (marked as group 1), soil types around Miboro Dam (marked as group 2), and fillings of Miboro Dam (marked as group 3), as shown in Figure 12. It is obvious that soil samples in group 1 and group 2 have optimum saturation degree $S_{\text {ropt }}$ that increases with the maximum dry density $\rho_{d \max }$. This is comprehensible since larger $S_{\text {ropt }}$ implies a smaller air void in the soil mass and aids in promoting $\rho_{d \max }$. However, $S_{\text {ropt }}$ of samples in group 3, series 1 , and group 3, series 2, levels off to a certain value, indicating that $S_{\text {ropt }}$ remains constant on the condition of increasing $\rho_{d \max }$ induced by rising compaction energy level. Although $\rho_{d \max }$ of coarse-grained soils can be improved by increasing compaction energy level and adjusting FC, only variation in FC could significantly promote the value of $S_{\text {ropt }}$. 


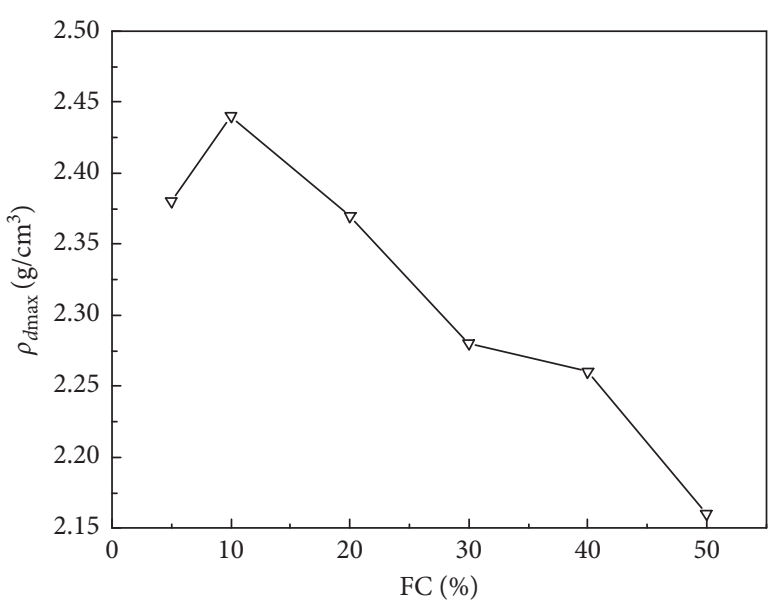

(a)

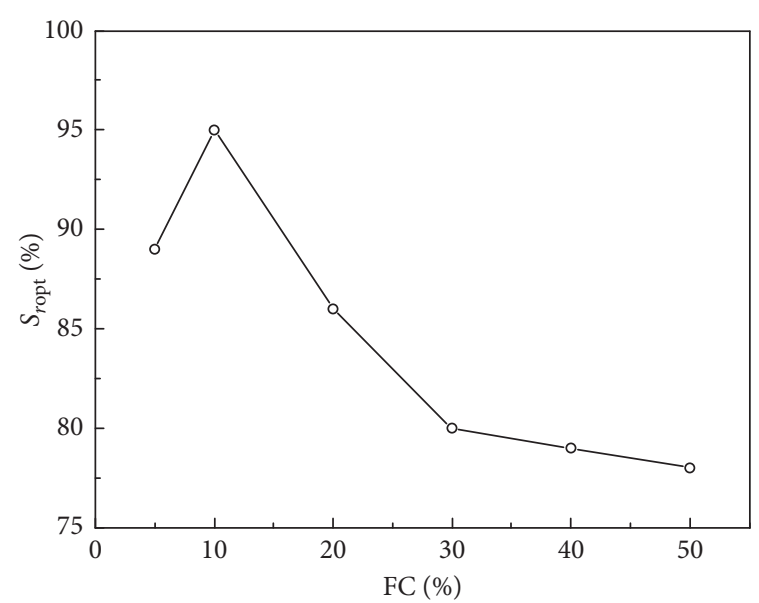

(b)

Figure 9: Compaction characteristics of tested gravel samples with different fine contents: (a) maximum dry density plotted against FC; (b) optimum saturation degree plotted against FC.

Moreover, the theoretical relationship between $\rho_{d \max }$ and $S_{\text {ropt }}$ is also plotted on the condition that specific gravity $G_{s}$ and air void ratio $v_{a}$ are given. Air void ratio $v_{a}$ is defined as the ratio of air void volume $V_{a}$ to total volume $V$ of the soil mass, as presented by the following equation [7]:

$$
v_{a}=\frac{V_{a}}{V}
$$

Given the basic fact that the total volume $V$ is the summation of void volume $V_{v}$ and solid soil volume $V_{s}$ and $V_{v}$ can be obtained by adding $V_{a}$ to pore water volume $V_{w}$, the equation can be rewritten as follows:

$$
v_{a}=\left(1-\frac{V_{w}}{V_{v}}\right)\left(1-\frac{V_{s}}{V}\right) .
$$

Furthermore, air void ratio $v_{a}$ can be expressed as follows:

$$
v_{a}=\left(1-S_{r}\right)\left(1-\frac{\rho_{d}}{\rho_{w} G_{s}}\right),
$$

where $\rho_{w}$ is the density of pore water. It should be noted that $\rho_{d \max }$ and $S_{\text {ropt }}$ are corresponding to the minimum air void ratio $v_{a \text { min }}$ for a given kind of soil sample compacted at a given compaction energy. Moreover, the theoretical relationship between $\rho_{d \max }$ and $S_{\text {ropt }}$ can be established with $G_{s}$ and $v_{a \min }$ known.

Based on equation (5), once compaction energy increases, $\rho_{d \max }$ also increases for a given kind of soil with FC fixed, and $S_{\text {ropt }}$ tends to level off to a certain value, which makes $v_{a \text { min }}$ decrease slightly. Nevertheless, for different kinds of soil samples with various FCs, $\rho_{d \max }$ increases with the increase in $S_{\text {ropt }}$. At the same time, the minimum air void ratio $v_{a \text { min }}$ decreases remarkably with the increase in $\rho_{d \max }$ and $S_{\text {ropt }}$. It thus can be concluded that $v_{a \text { min }}$ only decreases slightly for a given kind of soil although its $\rho_{d \max }$ increases significantly with compaction energy level. In other words, in spite of the fact that the increase in compaction energy can promote $\rho_{d \max }$, and it could not decrease $S_{\text {ropt }}$ and can just decrease $v_{a \text { min }}$ slightly. On the contrary, the increase in $\rho_{d \max }$ and $S_{r o p t}$ induced by the variation in FC will notably decrease $v_{a \text { min }}$ for soil samples with different FCs.

Furthermore, $v_{a \min }$ is plotted against FC for the three groups of soil samples, as shown in Figure 13. Soil samples in group 1 and group 2 present similar development characteristics. Samples of both groups have $v_{a \text { min }}$ that decreases with the increase in FC in the initial stage, but it will increase continuously with FC subsequently. This implies that FC could not only influence $\rho_{d \max }$ and $S_{\text {ropt }}$ but also has a remarkable effect on $v_{a \text { min }}$, indicating that fine particles could noticeably change the air void proportion in the coarsegrained soils. Besides, soil samples in group 3, series 1, and group 3, series 2, demonstrate quite close (but slightly decreasing) values of $v_{a \text { min }}$ on the condition of the same FC although their compaction energy is very different. Moreover, by comparing group 3 , series 1 , with group 3 , series 2 , FC of the dam fillings increases from $4.1 \%$ to $6.9 \%$ after passing the no. 4 sieve, and concomitantly, $v_{a \min }$ also presents a significant increasing trend. Therefore, FC is the dominant factor that controls the air void proportion in the coarse-grained soils. An optimum FC should be existed for the coarse-grained soils. Under the condition of optimum FC, the soils could present the lowest value of $v_{a \min }$ and the highest value of $\rho_{d \max }$, comparing to soils with other magnitudes of FCs. In the nature of things, the value of the optimum FC varies with the grading characteristics of the coarse-grained soil.

4.2. Soil Structure Analysis. It has been investigated that soil structure of coarse-grained soil can be classified into three kinds according to fine content (FC): void-existed skeleton structure, densely filled skeleton structure, and suspended skeleton structure $[2,34]$. Void ratio of coarse-grained soil is relatively high when FC stays at an extremely low level, leading to small value of dry density. At this time, coarse grains contact with each other to form soil skeleton, but the 

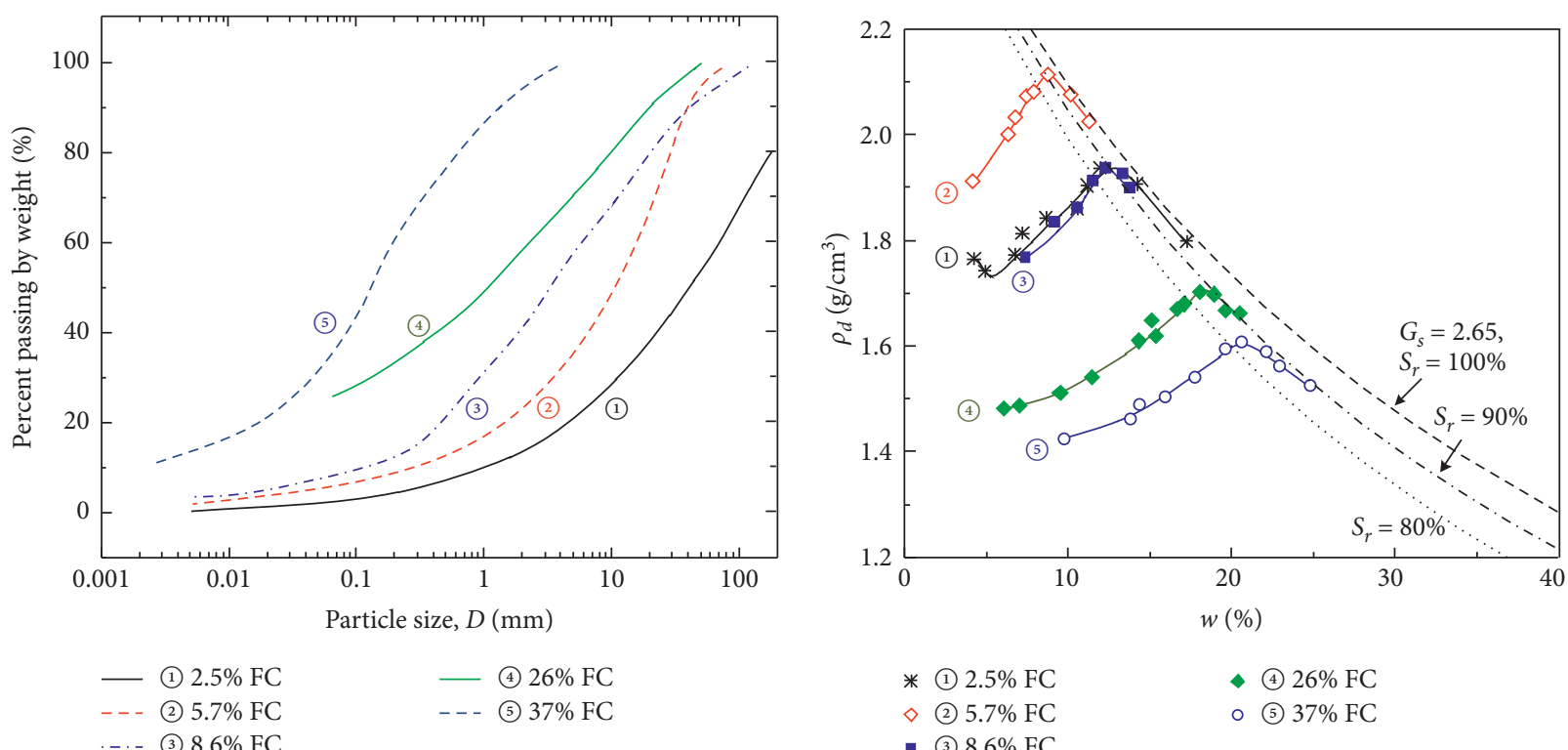

(a)

(b)

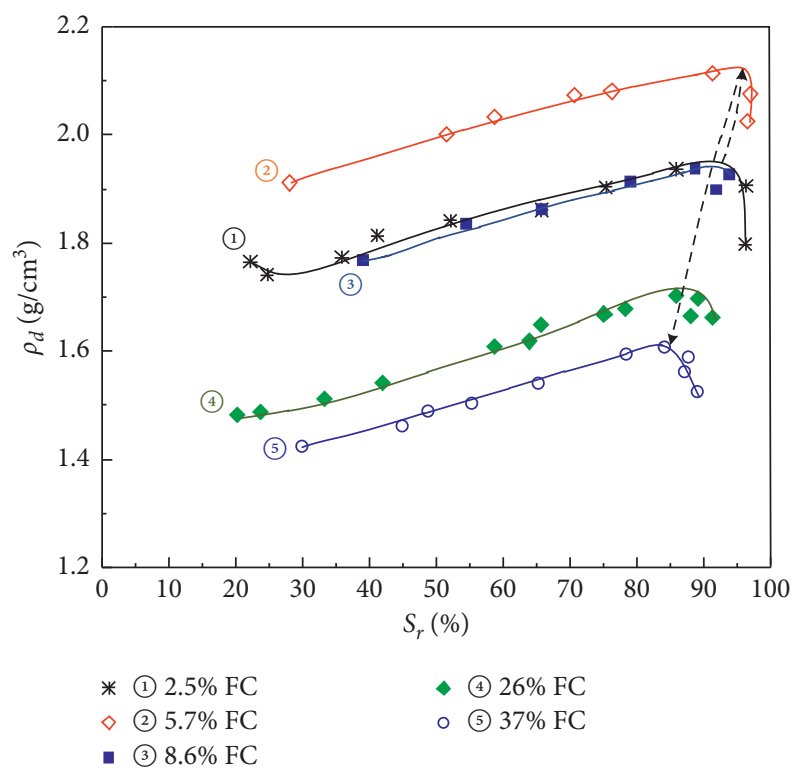

(c)

FiguRe 10: Five soil types sampled around Miboro Dam site [33]: (a) grading curves; (b) compaction curves; (c) dry density $\rho_{d}$ plotted against saturation degree $S_{r}$.

quantity of fine grains is too small to fill the voids established by coarse grain skeleton. Thus, a large amount of voids existed between soil skeleton structure, and the corresponding soil structure can be termed as a void-existed skeleton structure. When FC increases to a suitable amount, fine grain can just fill in the void formed by soil skeleton. At this point, coarse grain stays in close contact with fine grain, and void ratio of the soil reaches the minimum value, which is corresponding to the maximum dry density. The soil structure is very steady at this time and can be defined as a densely filled skeleton structure. As FC increases continuously, coarse grains start to be squeezed out by the excessive fine grains. Fine grains begin to encircle coarse ones and also participate in the establishment of soil skeleton. Therefore, dry density of soil skeleton is influenced due to the participant of fine grains, and void ratio begins to increase with the increase in FC. This corresponding status can be termed as a suspended skeleton structure [34]. The diagrams of these three kinds of soil structures are shown in Figure 14.

For tested gravel samples in this study (group 1), the 10\% FC sample tends to have the densely filled skeleton structure. The number of fine particles is just right to fill in the voids formed by the soil skeleton but not take part in the establishment of the skeleton. In the optimum water content $w_{o p t}$ (i.e., optimum saturation degree $S_{\text {ropt }}$ ) state, the $10 \%$ FC sample has the lowest value of the minimum air void ratio 


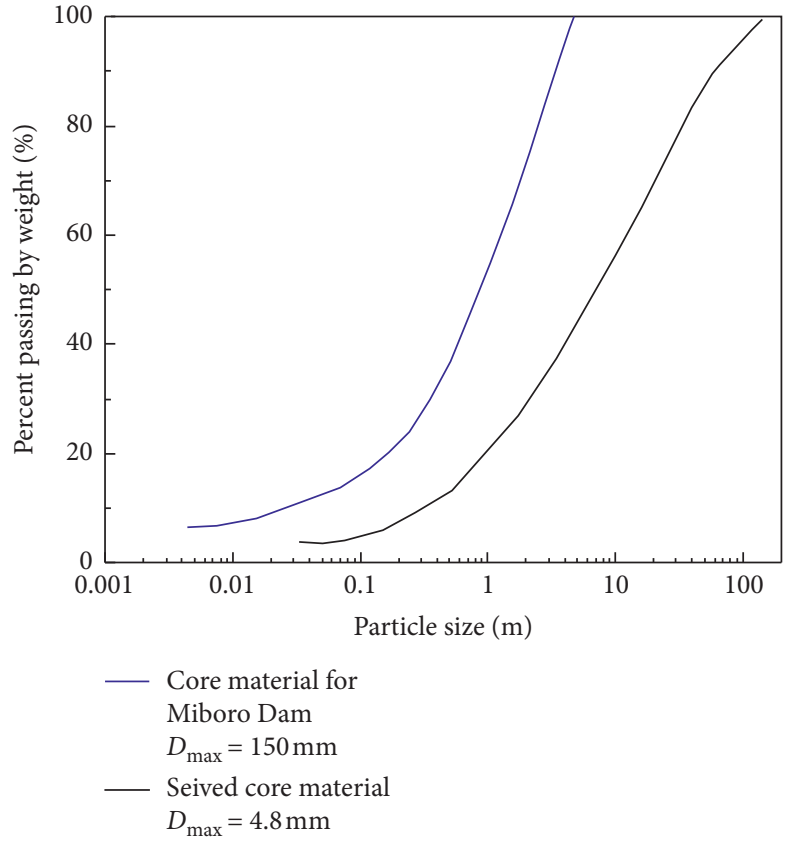

(a)

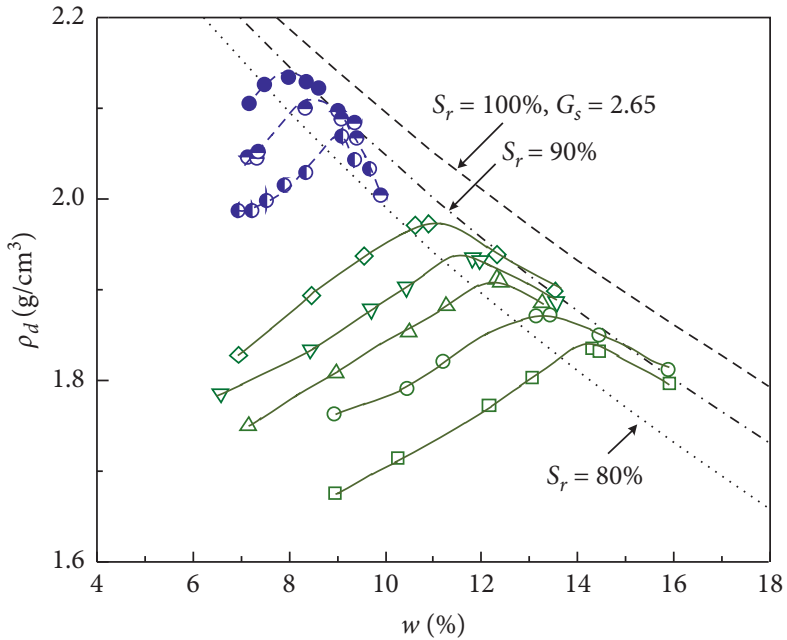

$\begin{array}{ll}\text { Field test } & \text { Lab test } \\ \text { Full grading }\left(D_{\max }=150 \mathrm{~mm}\right) & \text { Under No.4 portion } \\ & \left(D_{\max }=4.8 \mathrm{~mm}\right) \\ \text { - } \mathrm{N}=16 & \diamond 4.0 \mathrm{Ec} \\ \mathrm{N}=12 & \nabla 2.4 \mathrm{Ec} \\ & \triangle 1.6 \mathrm{Ec} \\ & \bigcirc 1.0 \mathrm{Ec} \\ & \square 0.6 \mathrm{Ec}\end{array}$

(b)

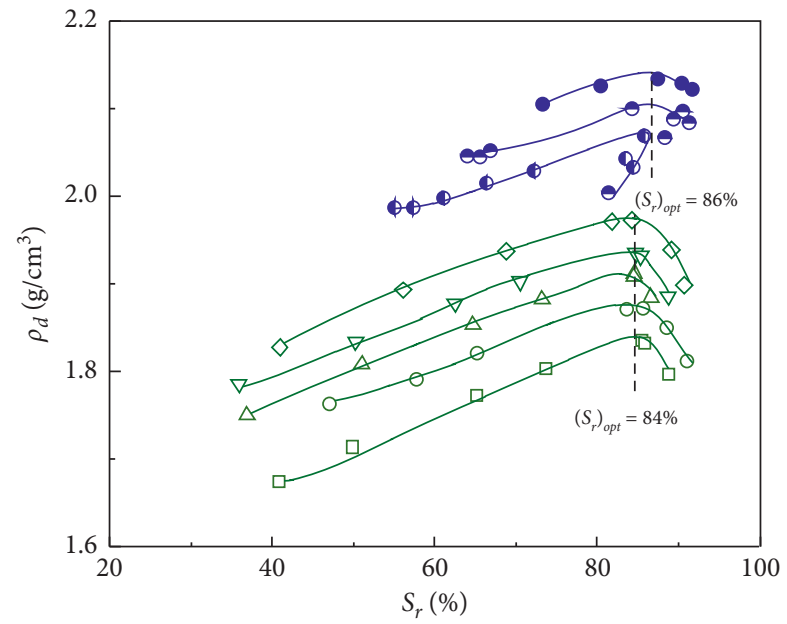

$\begin{array}{ll}\text { Field test } & \text { Lab test } \\ \text { Full grading }\left(D_{\max }=150 \mathrm{~mm}\right) & \text { Under No.4 portion } \\ & \left(D_{\max }=4.8 \mathrm{~mm}\right) \\ -\mathrm{N}=16 & \diamond 4.0 \mathrm{Ec} \\ \odot \mathrm{N}=12 & \nabla 2.4 \mathrm{Ec} \\ & \triangle 1.6 \mathrm{Ec} \\ & \bigcirc 1.0 \mathrm{Ec} \\ & \square 0.6 \mathrm{Ec}\end{array}$

(c)

Figure 11: Core material and sieved core material of Miboro Dam site [4, 5]: (a) grading curves; (b) compaction curves; (c) dry density $\rho_{d}$ plotted against saturation degree $S_{r}$.

$v_{a \min }$ compared to samples with other magnitudes of FCs, indicating that the $10 \%$ FC sample has the densest soil structure, as shown in Figure 14(b). As FC $<10 \%$, soil sample has a void-existed skeleton structure. A mass of voids is existed between soil skeleton due to the lack of fine grains, leading to $\rho_{d \max }$ and $S_{\text {ropt }}$ that are significantly lower than that of $10 \%$ FC sample (Figure 14(a)). However, soil sample with FC $>10 \%$ stays in suspended skeleton status. Since fine 


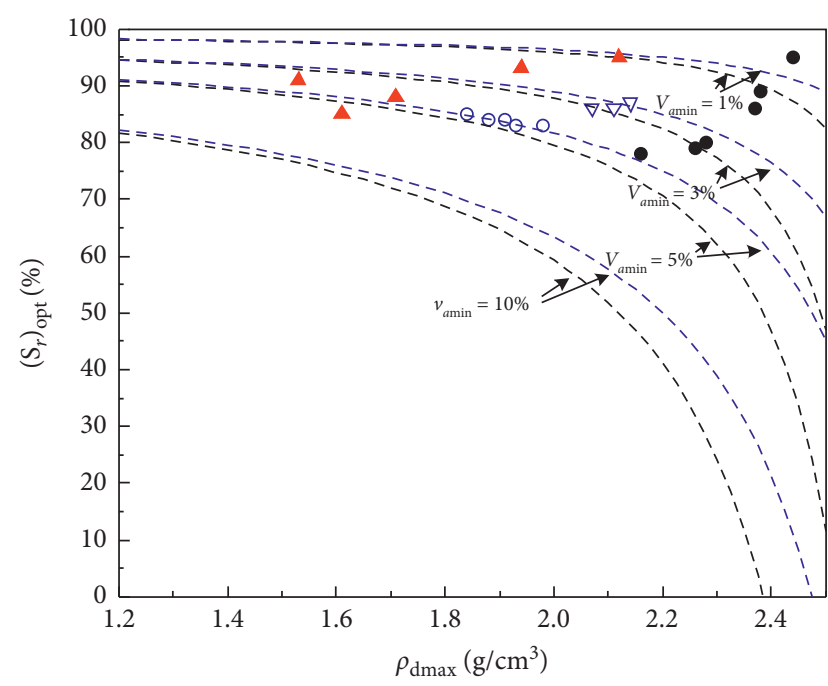

- Group 1: tested graded $\quad$ Group 3, series 2: sieved gravels, $4.5 \mathrm{Ec}$ material, $0.6 \mathrm{Ec} \sim 4.5 \mathrm{Ec}$

$\Delta$ Group 2: soil types around - - - Theoretical lines Miboro Dam, $1 \mathrm{Ec} \quad$ corresponding to $G_{s}=2.65$

$\nabla$ Group 3, series 1: core $\quad---$ Theoretical lines material, $\mathrm{N}=8,12,16 \quad$ corresponding to $G_{s}=2.75$

FIgURE 12: Optimum saturation degree $\left(S_{r}\right)_{\text {opt }}$ plotted against maximum dry density $\left(\rho_{d}\right)_{\max }$ for three groups of coarse soils.

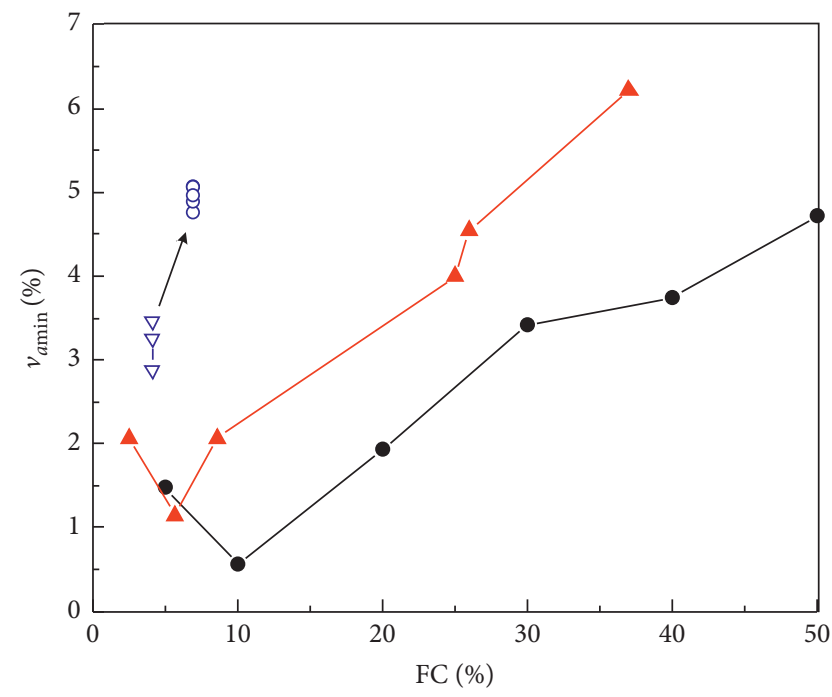

- Group 1: tested graded $\quad-\nabla$ - Group 3, series 1: core gravels material

- Group 2: soil types around -o— Group 3, series 2: sieved Miboro Dam material

FIGURE 13: Development of air void ratio $v_{a \text { min }}$ against FC for the three groups of coarse-grained soil.

grains are abundant to encircle the coarse particles, void ratio begins to increase remarkably, which certainly decrease $\rho_{d \max }$ and $S_{\text {ropt }}$, as presented in Figure 14(c). Besides, the $5.7 \%$ FC sample is likely to possess a densely filled skeleton structure for the soil samples around Miboro Dam (group 2). Sample with $\mathrm{FC}<5.7 \%$ tends to stay in a void-existed skeleton structure, while samples with FC $>5.7 \%$ have a suspended skeleton structure. It is worth noting that there is a difference between gravel samples of group 1 and gravelly soils of group 2. Gravel samples in group 1 have the coarsegrained portion that shares the same grading curves. However, gravelly soil samples around Miboro Dam in group 2 have quite different grading curves for the coarsegrained portion. Despite this, soils in group 2 also present a quasioptimum FC since the soils were sampled from adjacent sites. This is not difficult to understand for the optimum FC ranges within a moderate scope of less than 15\% in general despite the influence of grading features of coarsegrained portion.

Fillings of Miboro Dam in group 3 also comply with the soil structures summarized in Figure 14. When FC increases slightly from $4.1 \%$ to $6.9 \%$ after passing the No. 4 sieve, $v_{a \text { min }}$ rises significantly. It is clear that the sieved material (group 3, series 2) lies in a suspended skeleton soil structure since its $\rho_{d \max }$ and $S_{\text {ropt }}$ decrease as FC increases. However, confirmation for a structure type of the core material still needs further discussion. Nevertheless, given the fact that FC of the core material is rather close to that of the sieved material, the optimum FC corresponding to the densely filled skeleton structure should be close to or a bit less than $4.1 \%$; otherwise, significant increase in $v_{a \text { min }}$ could not be demonstrated after passing the sieve. In other words, the core material of Miboro Dam is likely to stay in a densely compacted skeleton structure or suspended skeleton structure.

4.3. Strength Properties Analysis. FC has a remarkable effect on the soil structure types of coarse-grained soils; thus, it could greatly influence $\rho_{d \max }$ and $S_{\text {ropt }}$ in a compaction test. By parity of reasoning, different soil structures due to various FC would also lead to variation in strength properties of graded gravels. The influence of FC on peak strength $\left(\sigma_{1}-\sigma_{3}\right)_{f}$ of tested graded gravel is presented in Figure 15. As shown in Figure 15(a), the OWC samples have peak strengths $\left(\sigma_{1}-\sigma_{3}\right)_{f}$ that increase with FCs on the condition of FC $<10 \%$. Once FC goes beyond $10 \%,\left(\sigma_{1}-\sigma_{3}\right)_{f}$ of graded gravels begins to decrease with the increase in FC. The $10 \%$ FC sample has the maximum peak strength $\left(\sigma_{1}-\sigma_{3}\right)_{f}$ in a triaxial test under a given confining pressure for OWC samples. Reason for this phenomenon is not difficult to find. The 10\% FC sample has the largest dry density and possesses the densely filled skeleton structure, which implies that the internal friction angle of the $10 \%$ FC sample is greater than that of gravel samples with other FCs. Moreover, the initial negative pore pressure (suction pressure) of the gravel samples with different FCs varies slightly (from $-3 \mathrm{kPa}$ to $0 \mathrm{kPa}$ ). At the same time, the shear strength envelop line of the $10 \%$ FC sample is the steepest among all the gravel samples with different FCs due to its maximum internal friction angle. Therefore, given the extended Mohr-Coulomb model, the diameter of Mohr's stress circle for the $10 \%$ FC sample should be the largest to make tangent with the envelop line, leading to the maximum $\left(\sigma_{1}-\sigma_{3}\right)$ f for $10 \%$ FC sample. Besides, $\left(\sigma_{1}-\sigma_{3}\right)_{f}$ of OWC gravel sample with a given FC increases with confining pressure 


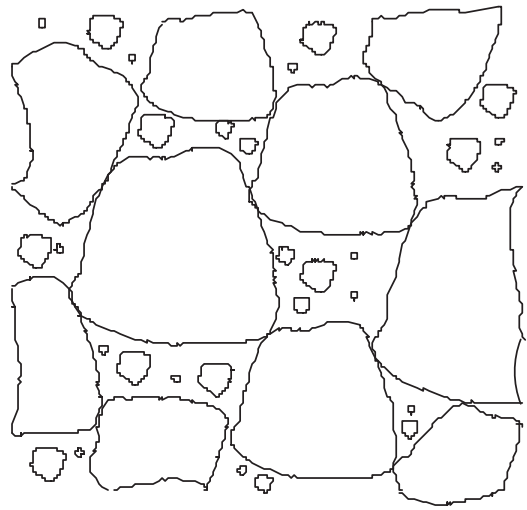

(a)

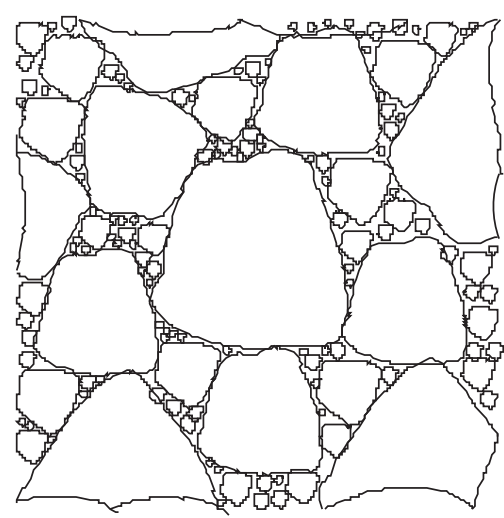

(b)

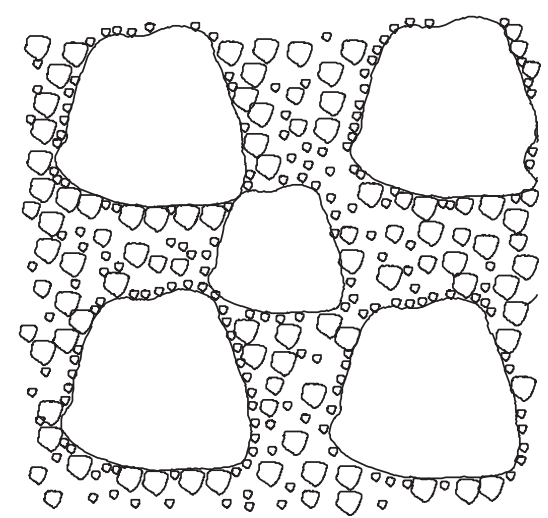

(c)

FIGURE 14: Three kinds of soil structures of coarse-grained soils: (a) void-existed skeleton structure; (b) densely filled skeleton structure; (c) suspended skeleton structure.

remarkably. Similarly, $\left(\sigma_{1}-\sigma_{3}\right)_{f}$ of SWC samples present the same development properties against FC as that of OWC samples, as shown in Figure 15(b).

Therefore, $10 \%$ FC sample demonstrate the maximum peak strength $\left(\sigma_{1}-\sigma_{3}\right)_{f}$ under a given confining pressure for samples that stay in OWC and SWC condition, respectively, which comes down in one continuous line with the compaction characteristics of graded gravels with different FCs. The variation in strength properties of gravel samples with different FCs also originates the different soil structures. The gravel sample stays in a void-existed skeleton structure on the condition that FC equals to 5\%. At this time, fine grain portion only partly filled with the voids, and puny constraining force is existed between coarse and fine grain portions. The shear strength of gravel samples mainly derives from frictional and occlusal forces between the coarse grains, and fine grain portion is difficult to play a substantial role in promoting the shear strength [34, 35]. The maximum dry density $\rho_{d \max }$ and optimum saturation degree $S_{\text {ropt }}$ of the 5\% FC sample remains relatively low compared with the $10 \%$ FC gravel sample. As a result, shear strength of 5\% FC sample also stays at a relatively low level. As FC increases to $10 \%$, tested gravel sample enters into densely filled skeleton structure. The embeddedness and squeeze effects between coarse and fine portions enhance significantly compared to the void-existed skeleton structure. At this point, shear strength of graded gravel sample is provided by both coarse grains and fine ones simultaneously. The $\rho_{d \max }$ and $S_{\text {ropt }}$ of the $10 \%$ FC sample reach the highest value compared with gravel samples with other magnitudes of FC, leading to the maximum peak shear strength $\left(\sigma_{1}-\sigma_{3}\right)_{f}$. When FC goes beyond $10 \%$, the frictional and occlusal forces between coarse grains are weakened due to the squeeze effect of the extra fine portion, resulting in the decrease in shear strength compared with the $10 \%$ FC gravel sample.

Furthermore, by comparing Figures 15(a) and 15(b), the variation in $\left(\sigma_{1}-\sigma_{3}\right)_{f}$ under different confining pressures is plotted against FC for gravel samples after saturation, as shown in Figure 16. The variation in $\left(\sigma_{1}-\sigma_{3}\right)_{f}$ is calculated by the following equation:

$$
\Delta\left(\sigma_{1}-\sigma_{3}\right)_{f}=\frac{\left(\sigma_{1}-\sigma_{3}\right)_{f 1}-\left(\sigma_{1}-\sigma_{3}\right)_{f 2}}{\left(\sigma_{1}-\sigma_{3}\right)_{f 2}}
$$

where $\left(\sigma_{1}-\sigma_{3}\right)_{f 1}$ is the peak strength of SWC sample and $\left(\sigma_{1}-\sigma_{3}\right)_{f 2}$ is the peak strength of OWC sample.

It can be seen that the peak strength $\left(\sigma_{1}-\sigma_{3}\right)_{f}$ of $10 \%$ FC sample decreases by $15 \%-20 \%$ after saturation. However, $5 \%$ FC sample and 20\% FC sample have peak strengths that rise by $10 \%-35 \%$ after saturation. Reason for this phenomenon can be deduced that variation in strength properties of gravel samples after saturation depends on both softening effect of pore water and strengthening effect of negative pore pressure. On the one hand, softening effect of pore water is intensified after saturation, leading to the decrease in strength properties of gravel samples. On the other hand, negative pore pressure also increases after saturation on the undrained condition. The accumulated negative pore pressure will undoubtedly promote the effective confining pressure, which further increases the peak strength of gravel samples. Therefore, the variation in strength properties is determined by whether softening effect of pore water or strengthening effect of negative pore pressure lies in the dominant position.

Looking back at Figure 8, the $10 \%$ FC sample has the maximum negative pore pressure on the condition of three different levels of confining pressure compared with the $5 \%$ FC and 20\% FC samples. The average values of negative pore pressure for the $10 \% \mathrm{FC}$ sample are $-52.4 \mathrm{kPa}$ and $-61.0 \mathrm{kPa}$ for OWC and SWC conditions, respectively. Nevertheless, the $5 \%$ FC sample and $20 \%$ FC sample have average values of negative pore pressure that equals to $-25.0 \mathrm{kPa}$ and $-27.8 \mathrm{kPa}$ for OWC condition. Besides, negative pore pressures of the $5 \%$ FC sample and $20 \%$ FC sample average at $-42.0 \mathrm{kPa}$ and $-49.9 \mathrm{kPa}$, respectively, for SWC condition. Therefore, the average negative pore pressure of the $10 \% \mathrm{FC}$ sample only increases $16 \%$ for the SWC samples compared with the OWC samples. In contrast, the 5\% FC and 20\% FC samples have average negative pore pressures that increases by $68 \%$ and $79 \%$ after saturation, respectively. The variation in negative pore pressure is also closely related with soil 


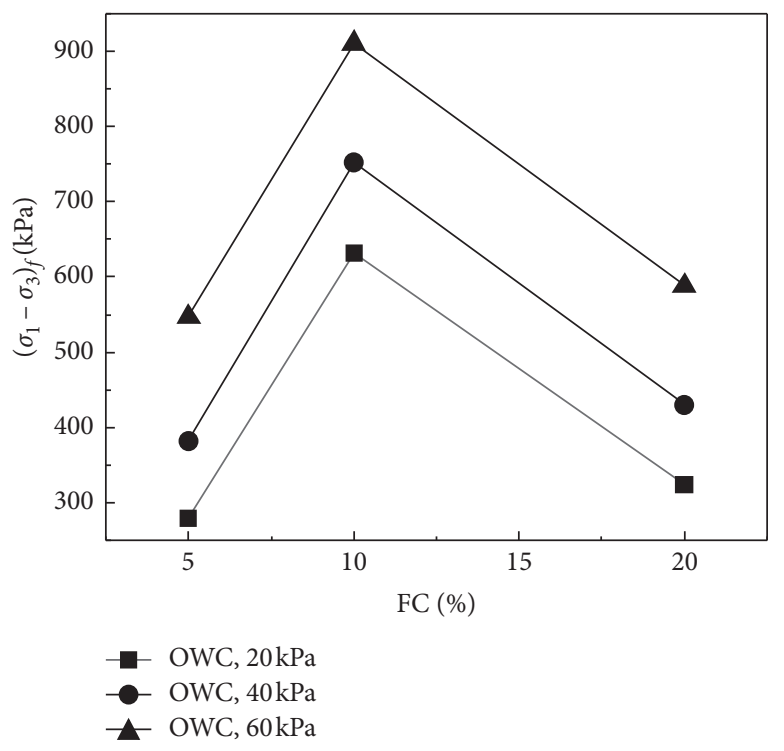

(a)

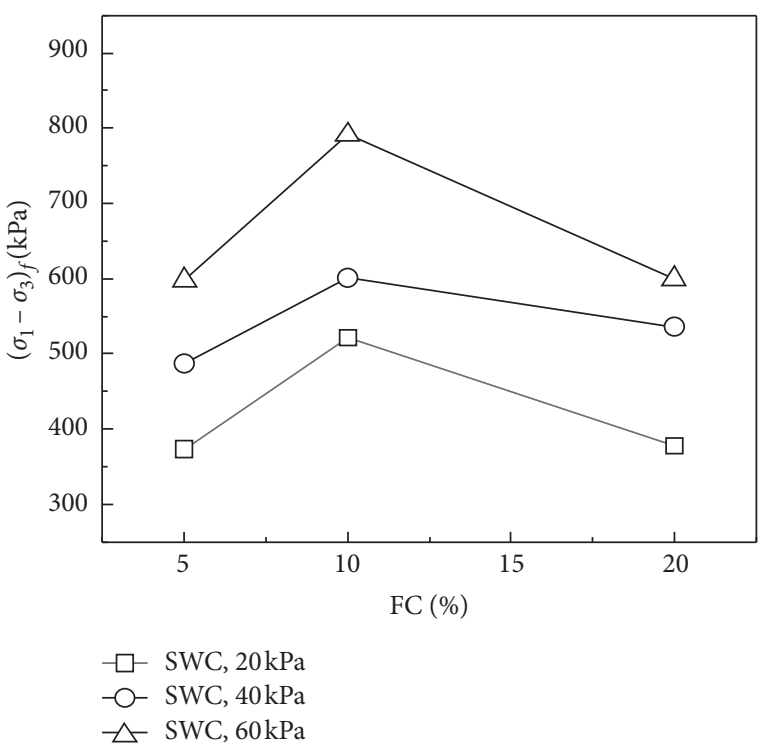

(b)

FIGURE 15: Relationship between FC and peak strength of graded gravels: (a) OWC samples; (b) SWC samples.

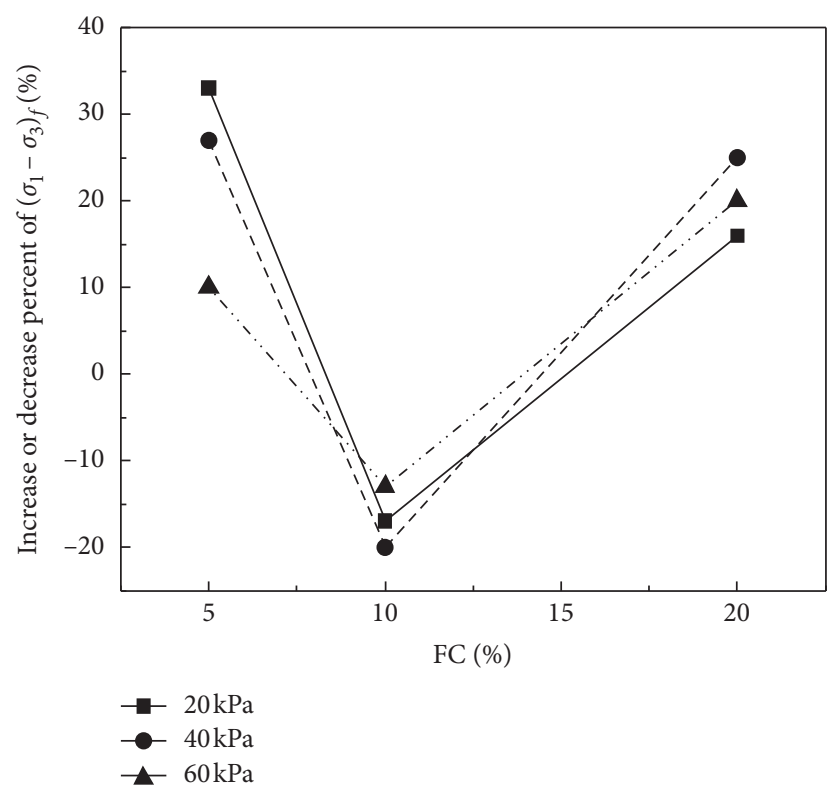

Figure 16: Increase or decrease percent of $\left(\sigma_{1}-\sigma_{3}\right)_{f}$ for gravel samples against FC after saturation.

structure types [34]. The 10\% FC sample has the densely compacted soil structure. The dense soil structure contributes to the accumulation of negative pore pressure in a triaxial test and results in a higher negative pore pressure compared with samples with other FCs even though the sample lies in OWC condition. Therefore, the increase in negative pore pressure after saturation is more difficult for the $10 \%$ FC sample compared with samples with other FCs. On the contrary, the soil structure is relatively loose for samples with $5 \%$ and $20 \% \mathrm{FCs}$, and the negative pore pressures are relatively low in OWC condition. Thus, a significant increase in negative pore pressure is easier to be presented after saturation.

The increase in negative pore pressure for the $10 \% \mathrm{FC}$ sample after saturation is so small that the promotion of strengthening effect of negative pore pressure is too weak. Thus, softening effect induced by the increase in pore water after saturation is stronger than the strengthening effect of negative pore pressure for the $10 \% \mathrm{FC}$ gravel sample, leading to the decrease in $15 \%-20 \%$ for the peak strength $\left(\sigma_{1}-\sigma_{3}\right)_{f}$. However, the negative pore pressures of the $5 \%$ FC and $20 \%$ FC samples increase significantly after saturation. At this time, strengthening effect of negative pore pressure lies in the dominant position and facilitates the increase in peak strength $\left(\sigma_{1}-\sigma_{3}\right)_{f}$ by $10 \%-35 \%$. In other words, as the graded gravel has a densely filled skeleton structure, peak strength tends to decrease due to the softening effect of increased pore water after saturation; when the gravel sample stays in a voidexisted skeleton structure or suspended skeleton structure, peak strength is likely to increase on account of the significant increase in negative pore pressure after saturation. Therefore, the $10 \%$ FC sample presents different development properties of shear strength from the 5\% FC and 20\% FC samples in the case that the moisture condition transfers from $\mathrm{OWC}$ to SWC. Finally, it is worth noting that peak strength $\left(\sigma_{1}-\sigma_{3}\right)_{f}$ of gravel sample will decrease ordinarily after saturation in engineering practice, which can be attributed to the difficult accumulation of negative pore pressure in field conditions. Besides, it is also unsafe to improve the soil strength by controlling negative pore pressure practically.

\section{Conclusions}

Compaction test and triaxial test were performed in this study to investigate the compaction and strength properties of graded gravels with different fine contents. Soil structure types of these gravel samples were analyzed in detail to 
illustrate their mechanical properties. Some significant conclusions can be drawn as follows:

(1) An optimum fine content (FC) ordinarily exists for the coarse-grained soils. Comparing to soils with other magnitudes of FC, the maximum dry density $\rho_{d \max }$ and optimum saturation degree $S_{\text {ropt }}$ of the soils with the optimum FC have the highest values. Correspondingly, soils with optimum FC also demonstrate the maximum peak shear strength in a triaxial test. Although the value of optimum FC varies with the grading curves of the coarse-grained portion, it is expected that FC of the graded gravels can be reasonably controlled to obtain the soil structures that have the optimum mechanical behavior.

(2) Although the increase in compaction energy level can greatly rise the maximum dry density $\rho_{d \max }$ of the coarse-grained soils, it could not increase $S_{\text {ropt }}$ substantially and can just slightly decrease the minimum air void ratio $v_{a \text { min }}$, which implies that air void proportion of the samples at $\rho_{d \max }$ and $S_{\text {ropt }}$ state varies a little in spite of the increase in compaction energy. However, adjustment of FC could not only significantly increase $\rho_{d \max }$ but also remarkably increase $S_{\text {ropt }}$ and decrease $v_{a \text { min }}$. Therefore, the improvement in mechanical properties of gravel samples induced by FC adjustment can be attributed to the optimization of soil structure.

(3) As FC stays at the optimum value, fine grain portion is just right to fill with the void formed by the coarsegrained skeleton. The soil lies in a densely filled skeleton structure, which facilitates the optimum compaction and strength properties that are presented in the soil. Besides, the mechanical properties will be degraded whenever FC is lower than or goes beyond the optimum value since the variation in FC can loosen the soil structure.

(4) As moisture content transfers from OWC to SWC condition, development characteristics of strength properties of graded gravels differs significantly with FC in a triaxial test. The variation trend in strength properties after saturation is determined by both softening effect of pore water and strengthening effect of negative pore pressure. The $10 \%$ FC gravel sample has negative pore pressure that increases slightly after saturation, resulting in the decrease in peak shear strength due to the fact that softening effect of pore water is the dominant factor. Negative pore pressures of samples with other magnitudes of FCs increase remarkably after saturation, which facilitates the increase in peak strengths of gravel samples.

\section{Data Availability}

The test data used to support the findings of this study are included within the supplementary information file.

\section{Conflicts of Interest}

The authors declare that there are no conflicts of interest.

\section{Acknowledgments}

The authors would like to acknowledge the support of National Natural Science Foundation of China (grant nos. 51408491 and 51878560) and Chunhui Planning Project of Ministry of Education (grant no. z2016155).

\section{Supplementary Materials}

The supplementary material mainly includes the original test data of compaction tests and triaxial tests for the gravel samples investigated in this study. (Supplementary Materials)

\section{References}

[1] National Railway Administration of People's Republic of China, TB 10621-2014 Code for Design of High Speed Railway, China Railway Publishing House, Beijing, China, 2014, in Chinese.

[2] Q. G. Guo, The Engineering Properties and Application of Coarse Grained Soil, The Yellow River Water Conservancy Press, Henan, China, 1998, in Chinese.

[3] L. Chen, L. Qiao, and Q. Li, "Study on dynamic compaction characteristics of gravelly soils with crushing effect," Soil Dynamics and Earthquake Engineering, vol. 120, pp. 158-169, 2019.

[4] E. Mikuni, "Study on the properties of fill dam core material and its compaction (No. 1)," Monthly Journal of JGS, TsuchiTo-Kiso, vol. 10, no. 1, pp. 4-12, 1962, in Japanese.

[5] I. Asao, "About Miboro dam (paper related to No. 31 issue in 8th ICOLD), large dam," Journal of Japanese Commission on Large Dams, vol. 27, pp. 33-44, 1964, in Japanese.

[6] F. Tatsuoka, "Compaction characteristics and physical properties of compacted soil controlled by the degree of saturation, Keynote Lecture, Deformation characteristics of geomaterials," in Proceedings of the 6th International Conference on Deformation Characteristics of Geomaterials, pp. 40-78, Buenos Aires, Argentina, November 2015.

[7] F. Tatsuoka and A. Gomes Correia, "Importance of controlling the degree of saturation in soil compaction linked to soil structure design," Transportation Geotechnics, vol. 17, pp. 3-23, 2018.

[8] S. Matsumura and F. Tatsuoka, "Effect of compaction conditions and fines content on cyclic undrained strength of saturated soils," Soil Dynamics and Earthquake Engineering, vol. 112, pp. 152-161, 2018.

[9] P. Nowak and P. Gilbert, Earthworks: A Guide, ICE Publishing, London, England, 2nd edition, 2015.

[10] C. W. W. Ng, G. Zheng, J. Ni, and C. Zhou, "Use of unsaturated small-strain soil stiffness to the design of wall deflection and ground movement adjacent to deep excavation," Computers and Geotechnics, vol. 119, 2020.

[11] P. Jenkins, "The strength of well graded cohesive fills," Ground Engineering, vol. 31, pp. 38-41, 1996.

[12] Z. Cao, J. Chen, Y. Cai, C. Gu, and J. Wang, "Effects of moisture content on the cyclic behavior of crushed tuff 
aggregates by large-scale tri-axial test," Soil Dynamics and Earthquake Engineering, vol. 95, pp. 1-8, 2017.

[13] Y. Cai, J. Chen, Z. Cao, and C. Gu, "Influence of grain gradation on permanent strain of unbound granular materials under low confining pressure and high-cycle loading," International Journal of Geomechanics, vol. 18, no. 3, 2018.

[14] F. Lekarp and A. Dawson, "Modelling permanent deformation behaviour of unbound granular materials," Construction and Building Materials, vol. 12, no. 1, pp. 9-18, 1998.

[15] P. K. Thakur, J. S. Vinod, and B. Indraratna, "Effect of confining pressure and frequency on the deformation of ballast," Géotechnique, vol. 63, no. 9, pp. 786-790, 2013.

[16] T. Ishikawa, Y. Zhang, T. Tokoro, and S. Miura, "Medium-size triaxial apparatus for unsaturated granular subbase course materials," Soils and Foundations, vol. 54, no. 1, pp. 67-80, 2014.

[17] B. Indraratna, N. Tennakoon, S. Nimbalkar, and C. Rujikiatkamjorn, "Behaviour of clay-fouled ballast under drained triaxial testing," Géotechnique, vol. 63, no. 5, pp. 410-419, 2013.

[18] Y. Yao, J. Ni, and J. Li, "Stress-dependent water retention of granite residual soil and its implications for ground settlement," Computers and Geotechnics, vol. 129, 2021.

[19] B. Babić, A. Prager, and T. Rukavina, "Effect of fine particles on some characteristics of granular base courses," Materials and Structures, vol. 33, no. 7, pp. 419-424, 2000.

[20] Z. Cao, J. Chen, Y. Cai, L. Zhao, C. Gu, and J. Wang, "Longterm behavior of clay-fouled unbound granular materials subjected to cyclic loadings with different frequencies," Engineering Geology, vol. 243, pp. 118-127, 2018.

[21] X. Chen and J. Zhang, "Effect of clay invasion on shear behavior and dilatancy of unbound aggregate subbase," Transportation Geotechnics, vol. 6, pp. 16-25, 2016.

[22] J. Ekblad and U. Isacsson, "Influence of water and mica content on resilient properties of coarse granular materials," International Journal of Pavement Engineering, vol. 9, no. 3, pp. 215-227, 2008.

[23] T. V. Duong, Y.-J. Cui, A. M. Tang et al., "Effects of water and fines contents on the resilient modulus of the interlayer soil of railway substructure," Acta Geotechnica, vol. 11, no. 1, pp. 51-59, 2016.

[24] Y.-J. Cui, "Mechanical behaviour of coarse grains/fines mixture under monotonic and cyclic loadings," Transportation Geotechnics, vol. 17, pp. 91-97, 2018.

[25] M. M. Jehring and C. A. Bareither, "Tailings composition effects on shear strength behavior of co-mixed mine waste rock and tailings," Acta Geotechnica, vol. 11, no. 5, pp. 1147-1166, 2016.

[26] M. M. Monkul, E. Etminan, and A. Şenol, "Coupled influence of content, gradation and shape characteristics of silts on static liquefaction of loose silty sands," Soil Dynamics and Earthquake Engineering, vol. 101, pp. 12-26, 2017.

[27] Q. Ni, T. S. Tan, G. R. Dasari, and D. W. Hight, "Contribution of fines to the compressive strength of mixed soils," Géotechnique, vol. 54, no. 9, pp. 561-569, 2004.

[28] T. D. Pitman, P. K. Robertson, and D. C. Sego, "Influence of fines on the collapse of loose sands," Canadian Geotechnical Journal, vol. 31, no. 5, pp. 728-739, 2011.

[29] American Society of Testing Materials (ASTM), ASTM D1557-09 Standard Test Methods for Laboratory Compaction Characteristics of Soil Using Modified Effort, ASTM International, West Conshohocken, PA, USA, 2009.

[30] Ministry of Housing and Urban-Rural Development of People's Republic of China, GB T50123-2019 Standard for
Geotechnical Testing Method, China Planning Press, Beijing, China, 2019, in Chinese.

[31] E. Selig and R. Ladd, "Preparing test specimens using undercompaction," Geotechnical Testing Journal, vol. 1, no. 1, pp. 16-23, 1978.

[32] C. W. W. Ng, A. Leung, and J. Ni, Plant-Soil Slope Interaction, Taylor \& Francis, Milton Park, Abingdon-on-Thames, Oxfordshire UK, 2019.

[33] Japanese Geotechnical Society, Interpretation of the Results of Ground Investigation and Soil Testing and Their Application Cases, Chapter 8 Permeability Tests, Japaese Geotechnical Society, Tokyo, Japan, 1979, pp. 336-337, in Japanese.

[34] Y. S. Ye, "Railway subgrade filling material classification," China Railway Science, vol. 25, no. 2, pp. 36-42, 2004, in Chinese.

[35] G. Cai, S. Chen, Y. Zhou et al., "Experimental study on influence of coarse grain content on strength and deformation characteristics of gravel soil," Water Resources and Hydropower Engineering, vol. 51, no. 1, pp. 187-195, 2020, in Chinese. 